\title{
Training programs to improve identification of sick newborns and care-seeking from a health facility in low- and middle-income countries: a scoping review
}

\author{
Alastair Fung ${ }^{1 *}$, Elisabeth Hamilton ${ }^{2}$, Elsabé Du Plessis ${ }^{2}$, Nicole Askin ${ }^{3}$, Lisa Avery ${ }^{4}$ and Maryanne Crockett ${ }^{5}$
}

\begin{abstract}
Background: Most neonatal deaths occur in low- and middle-income countries (LMICs). Limited recommendations are available on the optimal personnel and training required to improve identification of sick newborns and careseeking from a health facility. We conducted a scoping review to map the key components required to design an effective newborn care training program for community-based health workers (CBHWs) to improve identification of sick newborns and care-seeking from a health facility in LMICs.

Methods: We searched multiple databases from 1990 to March 2020. Employing iterative scoping review methodology, we narrowed our inclusion criteria as we became more familiar with the evidence base. We initially included any manuscripts that captured the concepts of "postnatal care providers," "neonates" and "LMICs."We subsequently included articles that investigated the effectiveness of newborn care provision by CBHWs, defined as non-professional paid or volunteer health workers based in communities, and their training programs in improving identification of newborns with serious illness and care-seeking from a health facility in LMICs.

Results: Of 11,647 articles identified, 635 met initial inclusion criteria. Among these initial results, 35 studies met the revised inclusion criteria. Studies represented 11 different types of newborn care providers in 11 countries. The most commonly studied providers were community health workers. Key outcomes to be measured when designing a training program and intervention to increase appropriate assessment of sick newborns at a health facility include high newborn care provider and caregiver knowledge of newborn danger signs, accurate provider and caregiver identification of sick newborns and appropriate care-seeking from a health facility either through caregiver referral compliance or caregivers seeking care themselves. Key components to consider to achieve these outcomes include facilitators: sufficient duration of training, refresher training, supervision and community engagement; barriers: context-specific perceptions of newborn illness and gender roles that may deter care-seeking; and components with unclear benefit: qualifications prior to training and incentives and remuneration.
\end{abstract}

\footnotetext{
*Correspondence: alastair.fung@sickkids.ca

${ }^{1}$ Hospital for Sick Children, Division of Paediatric Medicine, University

of Toronto, 555 University Ave., Rm 10402, Black Wing, Toronto, Ontario

M5G 1X8, Canada

Full list of author information is available at the end of the article
}

(c) The Author(s) 2021. Open Access This article is licensed under a Creative Commons Attribution 4.0 International License, which permits use, sharing, adaptation, distribution and reproduction in any medium or format, as long as you give appropriate credit to the original author(s) and the source, provide a link to the Creative Commons licence, and indicate if changes were made. The images or other third party material in this article are included in the article's Creative Commons licence, unless indicated otherwise in a credit line to the material. If material is not included in the article's Creative Commons licence and your intended use is not permitted by statutory regulation or exceeds the permitted use, you will need to obtain permission directly from the copyright holder. To view a copy of this licence, visit http://creativecommons.org/licenses/by/4.0/. The Creative Commons Public Domain Dedication waiver (http://creativeco mmons.org/publicdomain/zero/1.0/) applies to the data made available in this article, unless otherwise stated in a credit line to the data. 
Conclusion: Evidence regarding key components and outcomes of newborn care training programs to improve CBHW identification of sick newborns and care-seeking can inform future newborn care training design in LMICS. These training components must be adapted to country-specific contexts.

Keywords: Newborn care, Newborn, Neonatal, Training, Care-seeking, Low- and middle-income countries, Human resources for health

\section{Background}

While neonatal and child mortality decreased substantially worldwide from 1990 to 2019, the burden of under-five mortality remains significant in low- and middle-income countries (LMICs) [1]. Indeed, LMICs did not achieve the Millennium Development Goal 4 (MDG4), which aimed to reduce under-five mortality by two-thirds between 1990 and 2015 [2]. The MDG4 translated to a $4 \%$ annual rate of decrease in under-five mortality during this period [2]. From 1990 to 2000, the annual global rate of decrease in under-five mortality only reached an average of $2 \%$ per year [3].

Moreover, survival rates differ among age groups of children younger than five years with a particularly high burden in the neonatal period (first 28 days of life). In $2019,47 \%$ (2.4 million) of under-5 deaths occurred among neonates [1]. Mortality for neonates has also decreased at a much slower rate than those recorded for post-neonatal children [1]. Most neonatal deaths occur in LMICs with sub-Saharan Africa accounting for $42 \%$ of neonatal mortality in 2019, and Central and Southern Asia accounting for 37\% [1]. Thus, reducing under-five mortality requires heightened attention to improving neonatal care in LMICs.

Over the past two decades, considerable progress has been made in improving the proportion of births attended by skilled health personnel (i.e., doctors, nurses or midwives) and occurring in a health facility in LMICs. From the period 2000-2006 to 2014-2020, the proportion of births occurring at a health facility in West and Central Africa, Eastern and Southern Africa, and South Asia increased from 38 to $55 \%, 37$ to $66 \%$, and 31 to $74 \%$, respectively [4]. While coverage of facility-based deliveries has improved in LMICs, community-based follow-up of infants, particularly high-risk small and sick newborns, remains important to reduce neonatal morbidity and mortality [5].

Of all neonatal deaths globally, about two thirds occur after the first $24 \mathrm{~h}$ of life and almost three-quarters of neonatal deaths occur during the first week of life [6]. Moreover, about one half of neonatal deaths due to sepsis in LMICs occur after the first week of life [7]. Studies in various LMIC settings have shown that caregiver delay in recognizing sick newborns and in deciding to seek care are major contributors to neonatal mortality
[8, 9]. A systematic review of care-seeking for neonatal illness in LMICs reported that a median of 59\% of caregivers seek any care for their neonate once they recognize their neonate is ill or suspected to be ill [10]. Thus, improving community-based recognition of sick newborns and care-seeking from a health facility is critical.

The World Health Organization (WHO) 2013 recommendations on postnatal care of the mother and newborn [11] and the WHO recommendations on newborn health updated in 2017 [18], provide a summary of the best practices and supporting evidence for the timing, number and place of postnatal contacts as well as the content of newborn care during the first six weeks after birth. These guidelines are targeted at first level health workers or community level workers in resource-limited settings [11]. However, there is no specific mention of the optimal personnel and training required for effective newborn care provision. Regarding the place of newborn care, one systematic review concluded that community health worker ( $\mathrm{CHW})$ home visits resulted in a significant (18\%) reduction in all-cause neonatal mortality compared to routine care [12]. A recent overview of systematic reviews provides evidence for interventions to prevent neonatal mortality but without specifically reviewing different care providers of these interventions or their training [13].

In 2015, the United Nations created the Sustainable Development Goals (SDGs) as the successor to the MDGs. Centred on reducing child mortality, SDG3.2 aims to decrease neonatal mortality to fewer than 12 deaths per 1000 livebirths and end preventable deaths of newborns and children under five years of age [14]. More than 60 countries are projected to miss this neonatal mortality target by 2030 and will need to accelerate progress to reach the target on time [1]. In light of these global goals and current trends, it is important to identify and map the optimal personnel and training required to deliver the most appropriate newborn care in LMICs. This scoping review aims to determine what is known from available literature about the relative effectiveness of community-based health worker (CBHW) newborn care providers and their training programs in LMICs in addition to mapping the key components necessary to design an effective CBHW newborn care training program and intervention to 
improve identification of sick newborns and care-seeking from a health facility in LMICs.

\section{Methods}

\section{Search strategy and selection criteria}

This study followed the PRISMA-ScR checklist (see Additional file 1) and the Joanna Briggs Institute (JBI) methodology for scoping reviews [15]. We employed an iterative approach to study selection whereby we narrowed our inclusion criteria as we became more familiar with the evidence base. Initial inclusion criteria were studies that: 1 ) included care providers for neonates defined as infants $\leq 28$ days; 2 ) compared care providers or compared specific care providers to routine or no care for neonates; and 3) were conducted in LMICs. Care providers were defined as supplemental personnel outside of the newborn's family offering newborn care. Newborn care practices were defined as any action taken by care providers that served to support the essential biological and psychosocial needs of the newborn following delivery to the first 28 days of life. Low- and middle-income economies were defined according to the World Bank classification [14]. No restrictions were placed on language.

A medical research librarian constructed the search strategy. An initial limited search of two databases (Medline and CINAHL) with search terms reflecting the concepts of "low/middle-income countries", "postnatal care" and "provider type" was performed. We conducted an analysis of the results from the preliminary search to inform the development of the full search strategy, which was conducted across Medline (Ovid), CINAHL (EBSCO), Global Health (Ovid), the Cochrane Library collection of databases (Wiley), and DARE (Database of Abstracts of Reviews of Effects) from 1990 to March 31, 2020. We also searched the grey literature including all registered clinical trials on clinicaltrials.gov. See Additional file 2 for the full electronic search strategy in Medline (Ovid).

Among the articles included in the initial search, major areas of study within newborn care included newborn resuscitation, breastfeeding promotion, kangaroo mother care, umbilical cord care, prevention of mother-to-child transmission of HIV (PMTCT), identification of sick newborns and care-seeking from a health facility. After reviewing these various areas, we decided by consensus to narrow our inclusion criteria to focus specifically on studies of CBHW newborn care provision and training programs to improve identification of sick newborns and care-seeking in community-based settings outside of the hospital and primary health care facilities. Thus, the revised inclusion criteria were studies that: 1) investigated the effectiveness of $\mathrm{CBHW}$ newborn care providers and their training programs to improve identification of newborns with serious illness and/or care-seeking from a health facility, and 2) occurred in community-based settings in urban or rural areas of LMICs.

We defined CBHWs as health workers who meet the following criteria: 1 ) have some training in carrying out functions related to biomedical health care delivery, 2) have no formal professional or paraprofessional certificate, 3) provide care in community settings, that is, at patients' homes or based at peripheral health posts not staffed by physicians or nurses, and not at primary health care facilities, and 4) are either paid or volunteer $[16,17]$. 'Newborns with serious illness' was defined as newborns with 'danger signs' which included the WHO newborn danger signs [18], WHO signs of possible serious bacterial infection [19] and variations of these lists of signs.

We excluded studies conducted in neonatal intensive care units or tertiary care centres, studies conducted in high-income countries, review articles, conference abstracts, study protocols, case reports, commentaries and editorials.

\section{Data analysis}

The total number of studies was divided among three reviewers (AF, EH and EdP) and two of the three reviewers independently performed the eligibility assessment for each study in a standardized manner using predefined inclusion and exclusion criteria, first in abstract form followed by full-text format. Disparities between reviewers were resolved by discussion and where there was still lack of agreement, a fourth reviewer (MC) was consulted.

Two reviewers (AF and EH) extracted the data from all included studies onto a data extraction form. Information collected included first author and year of publication, country and study setting, study design, characteristics of the neonatal subjects, characteristics of the newborn care providers, duration and content of training if available, the content and coverage of the intervention and the outcomes as they pertained specifically to the identification of newborns with serious illness and care-seeking from a health facility.

We did not perform a formal assessment of methodological quality as this is not a typical feature of scoping reviews [15].

\section{Results}

The flow diagram of study selection is shown in Fig. 1.

The search strategy identified 11,647 articles. After adjusting for duplicates, 9263 studies remained. Of these, 635 studies met the initial inclusion criteria. Within these results, 35 articles [20-54] detailing 28 studies met the revised inclusion criteria. The characteristics of the 35 included articles are summarized in Table 1 and in an expanded Table in Additional file 3. 


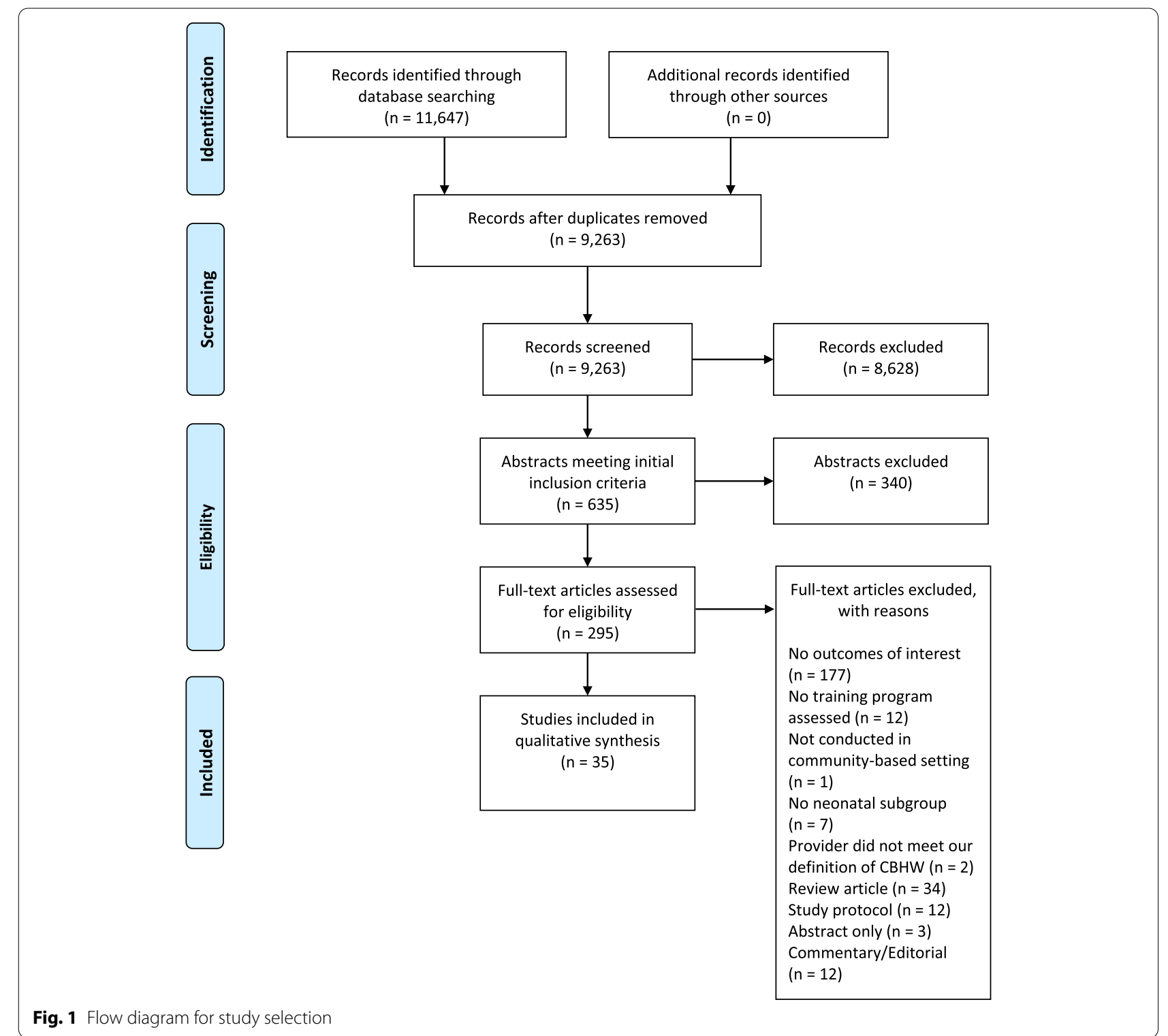

The included articles were published between 2005 and 2020. Studies represented 11 countries across three subcontinents (Fig. 2).

\section{Newborn care provider types}

Eleven community-based newborn care provider types were identified. These included community health workers (CHWs), village health workers (VHWs), traditional birth attendants (TBAs), accredited social health activists (ASHAs), auxiliary nurse midwives (ANMs), female community health volunteers (FCHVs), community-based surveillance volunteers (CBSVs), community volunteers (CVs), lady health workers (LHWs), health extension workers (HEW) and peer educators. The most common provider type was the $\mathrm{CHW}$.

\section{Platforms and timing of care delivery}

Thirty-one studies used home visits as the platform of care delivery. One study investigated women's group meetings [47]. Another study compared "high intensity" intervention, "low intensity" intervention and control groups, with "high intensity" consisting of CHW home visits and $\mathrm{CV}$ outreach and community engagement through group discussions and "low intensity" consisting of CV outreach and engagement activities only [32]. One study assessed CHW contacts with women either in their home or by mobile phone three days after delivery 


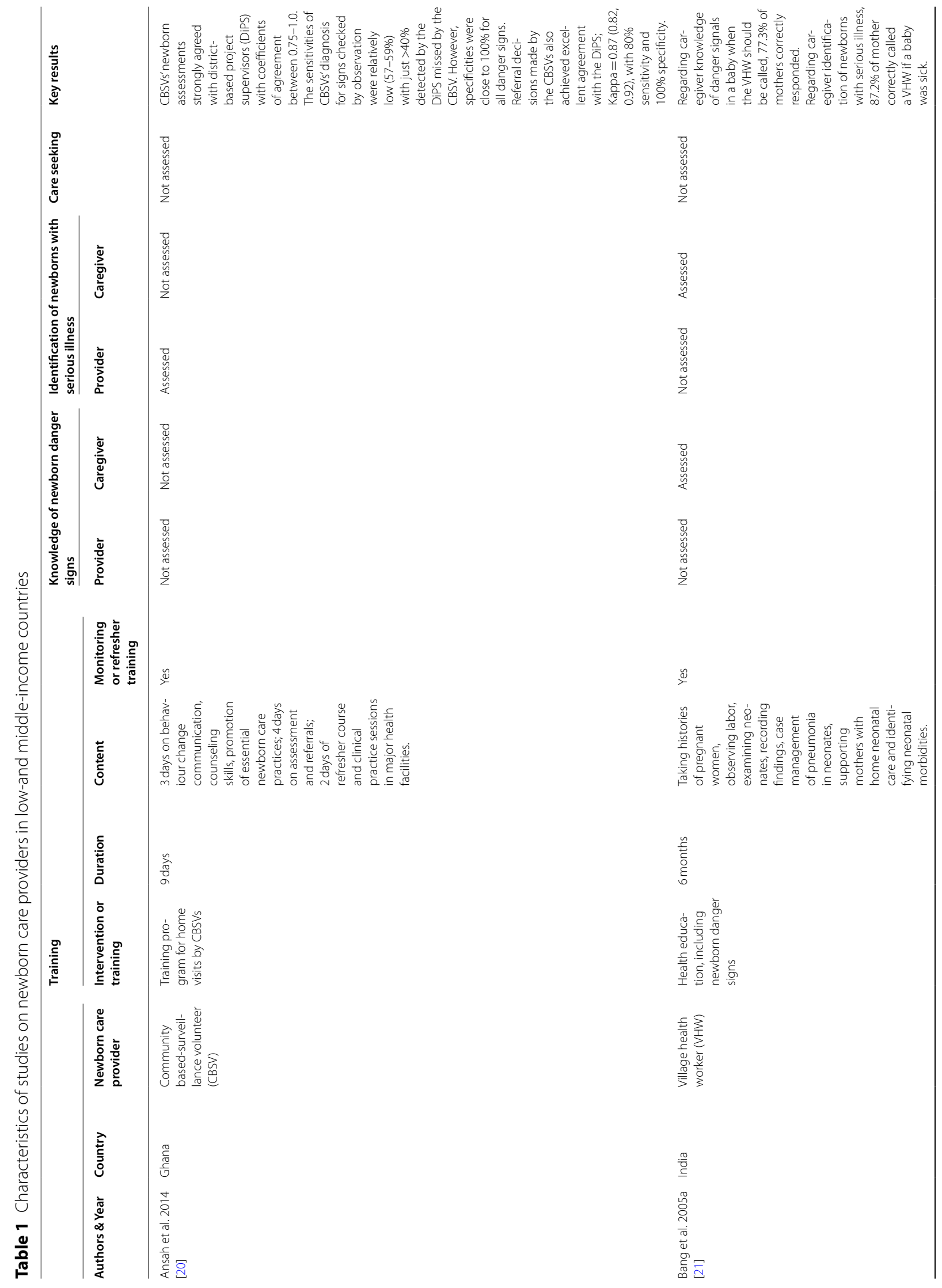




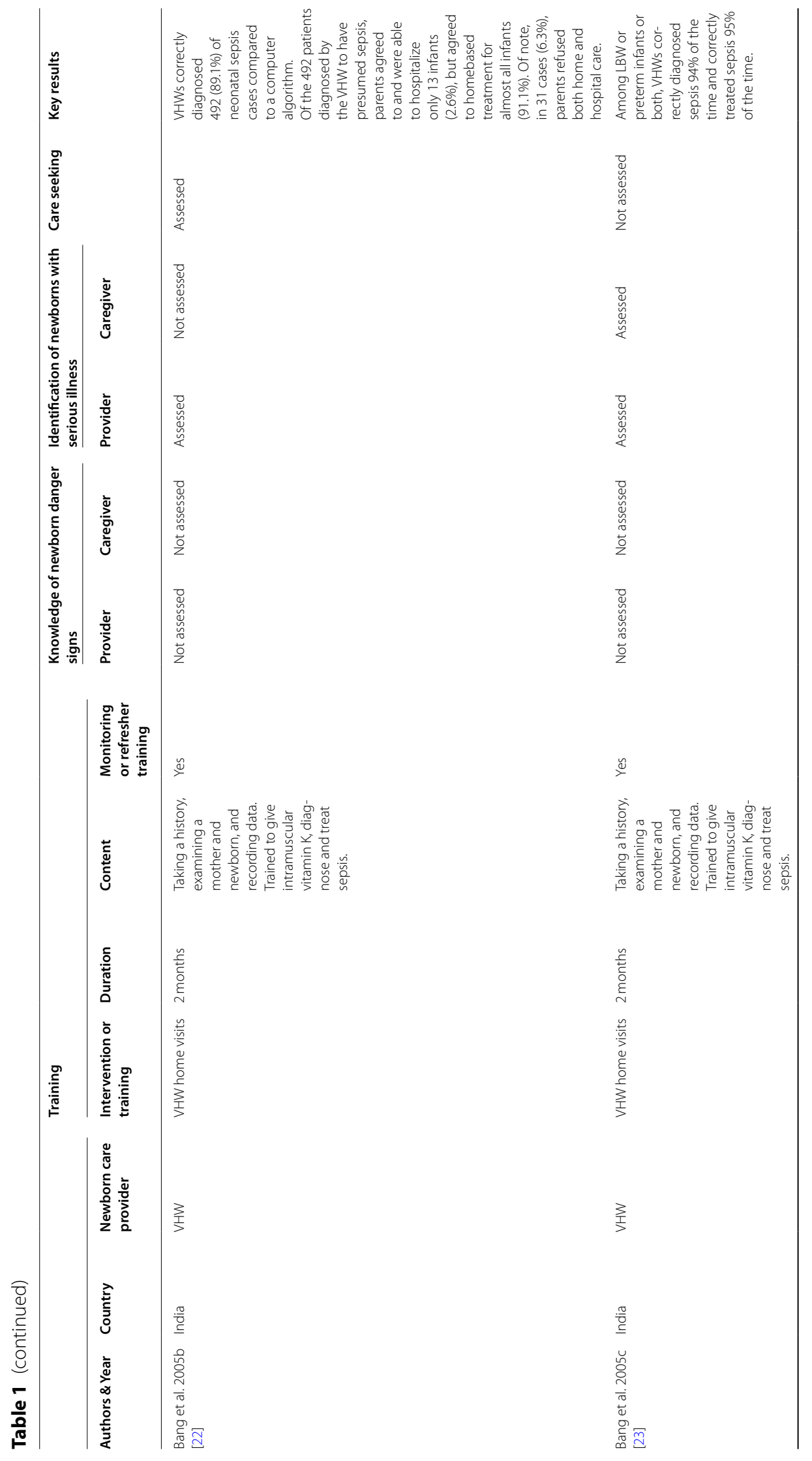




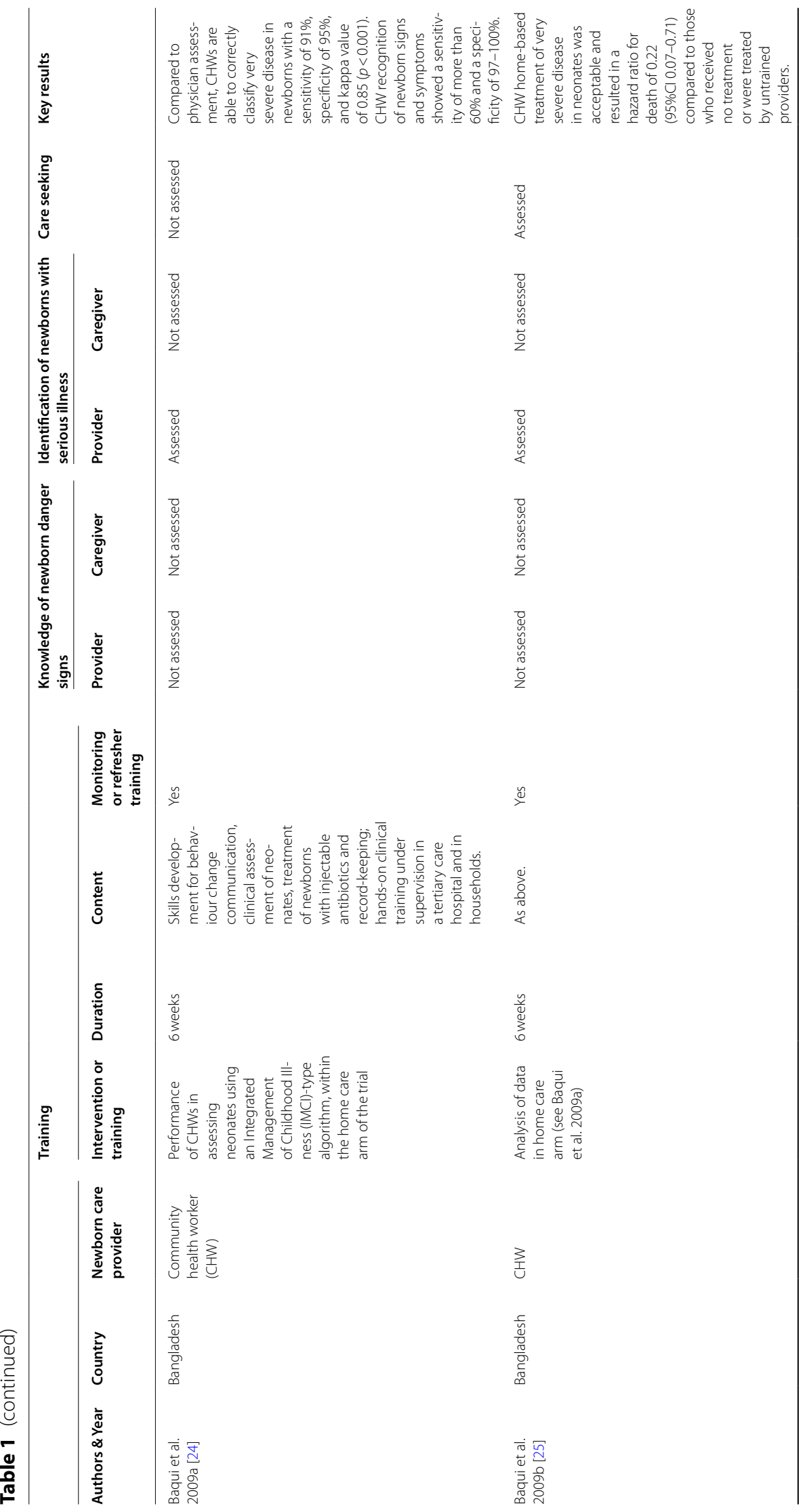




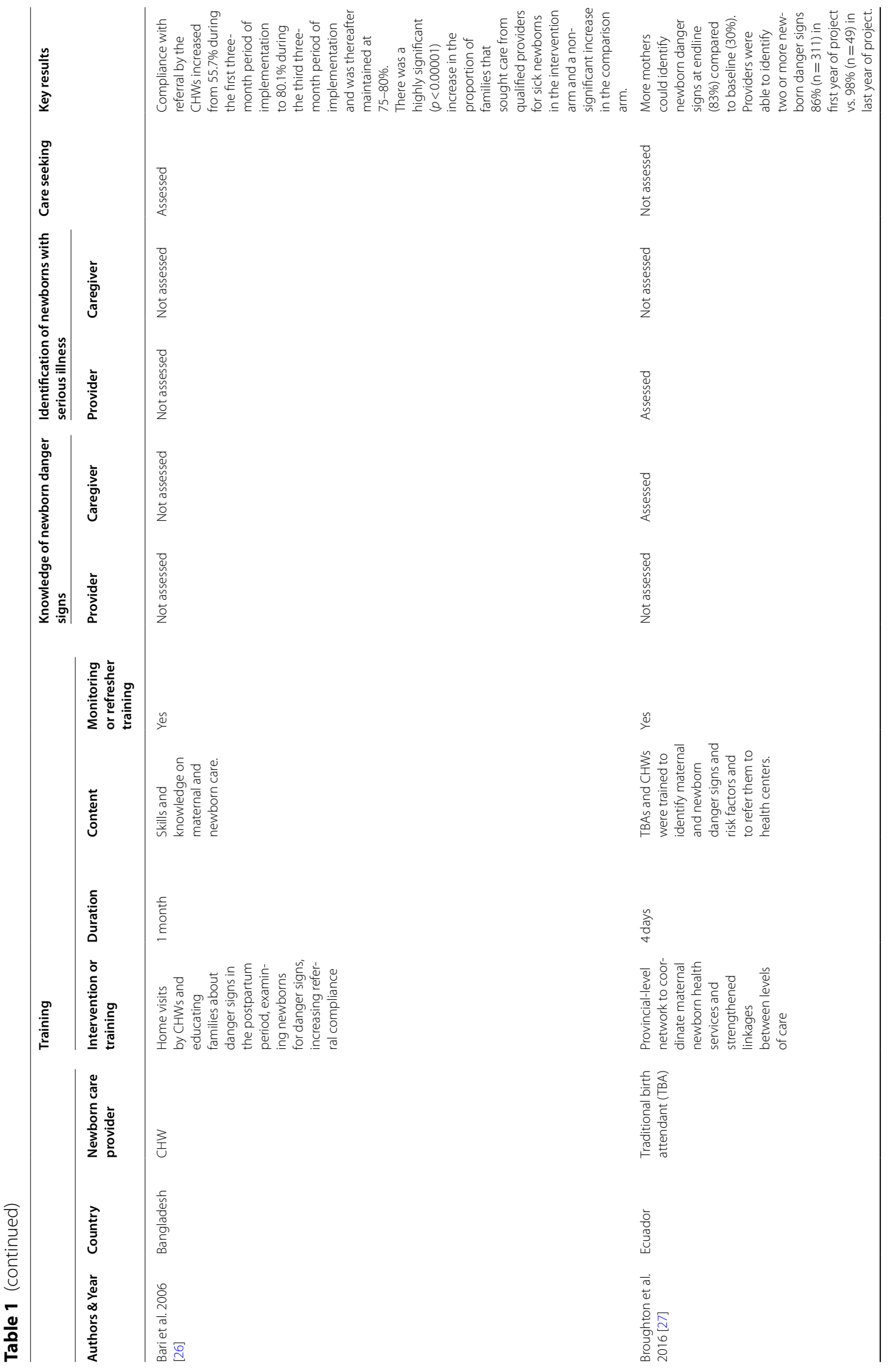




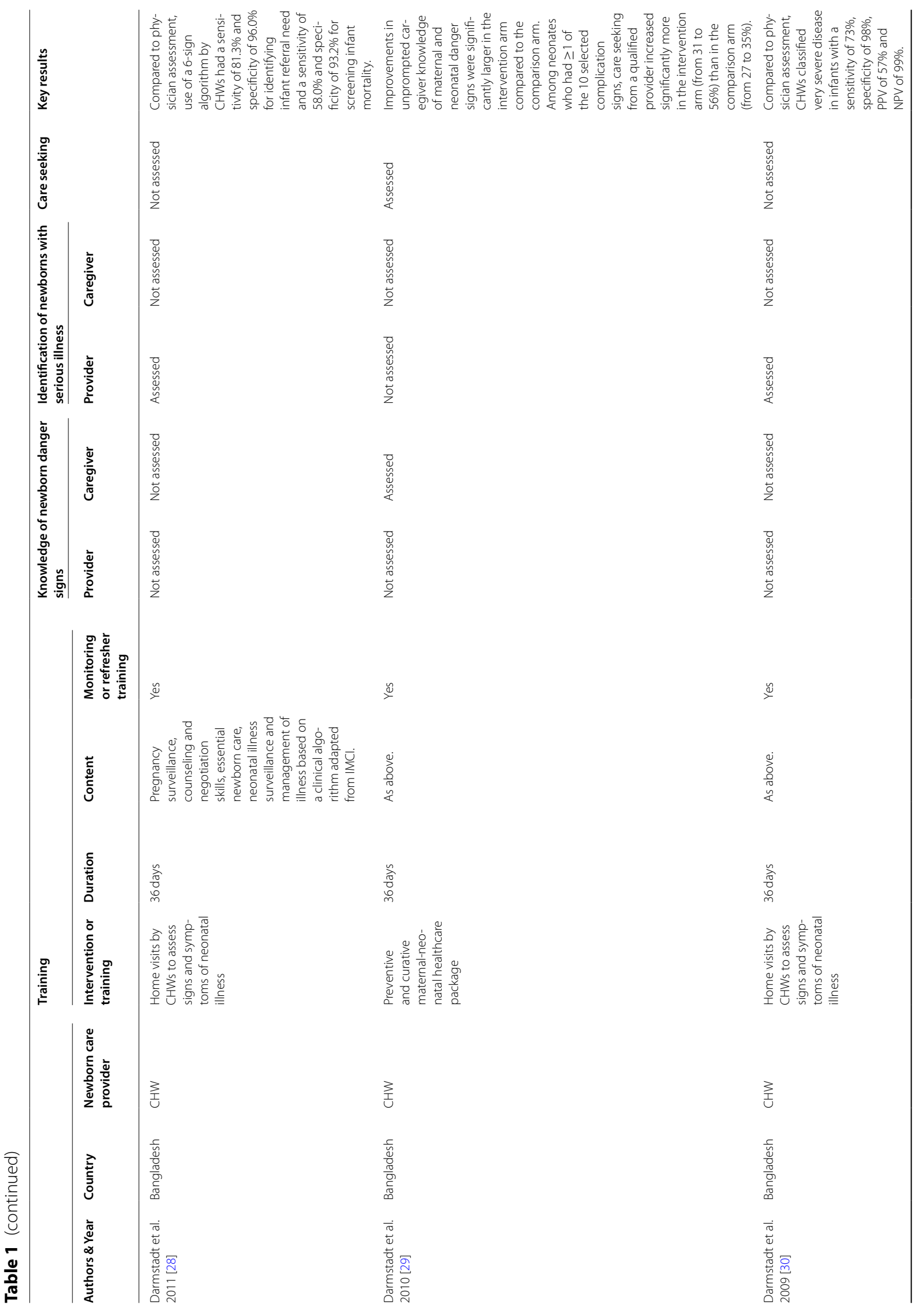




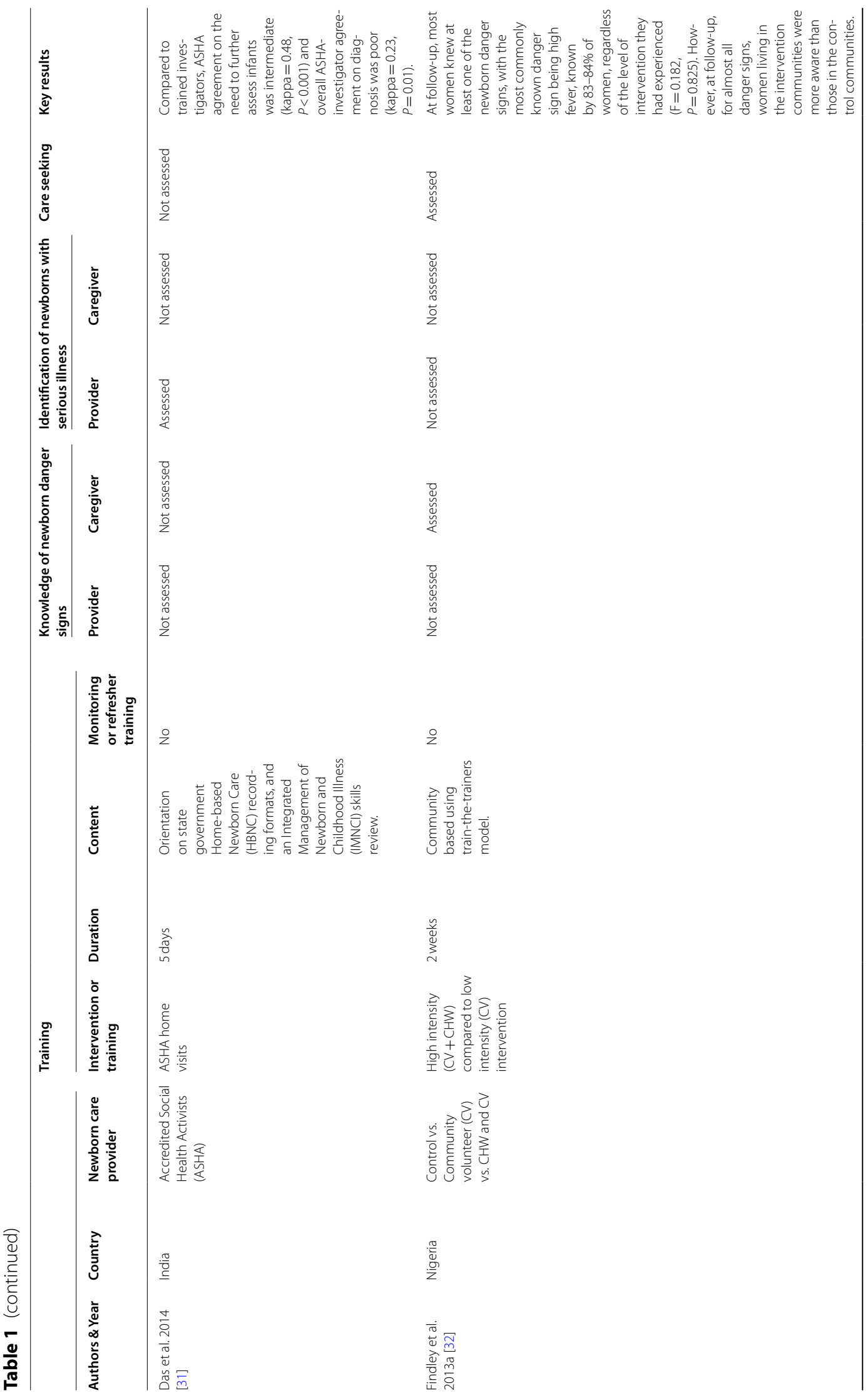




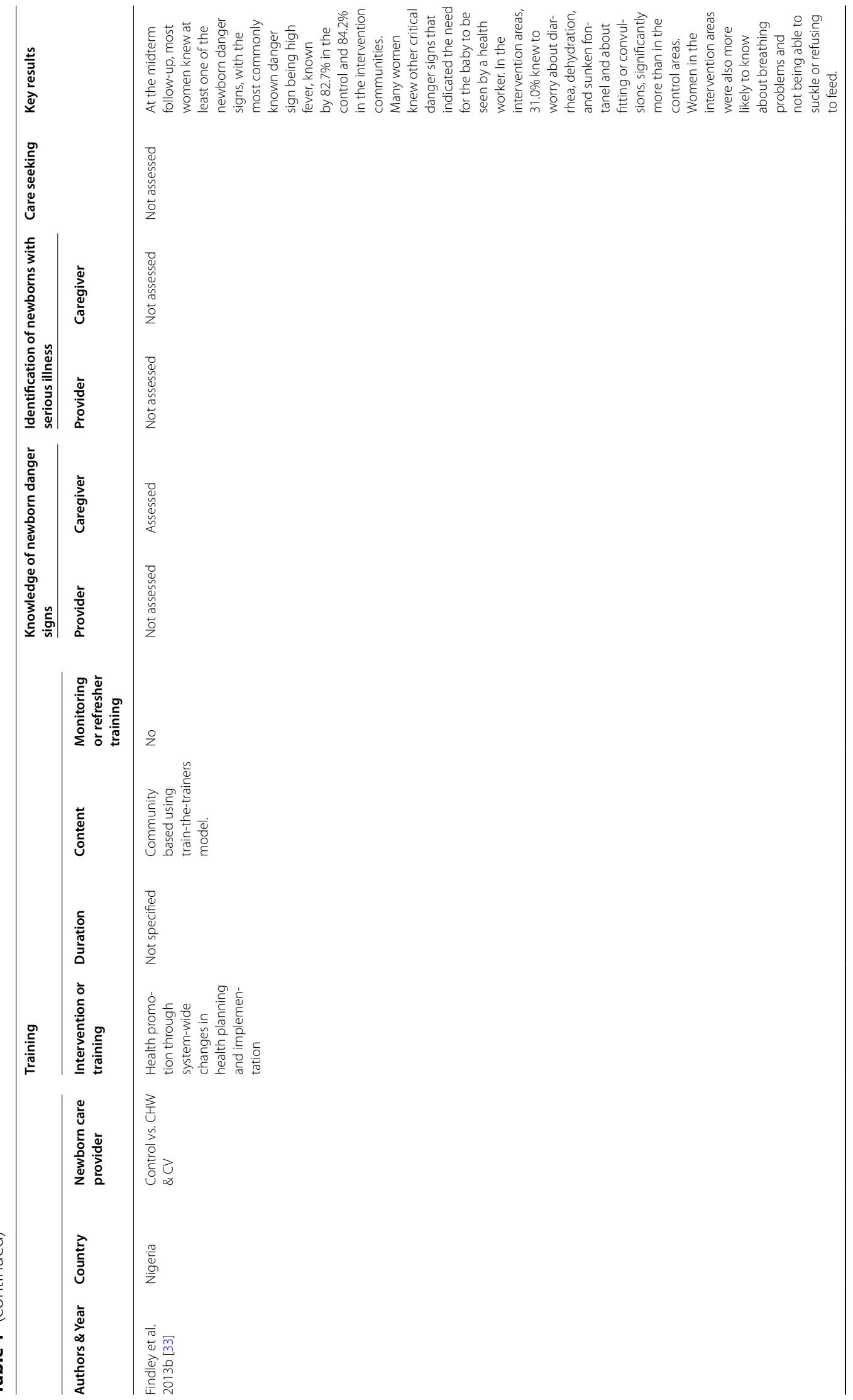




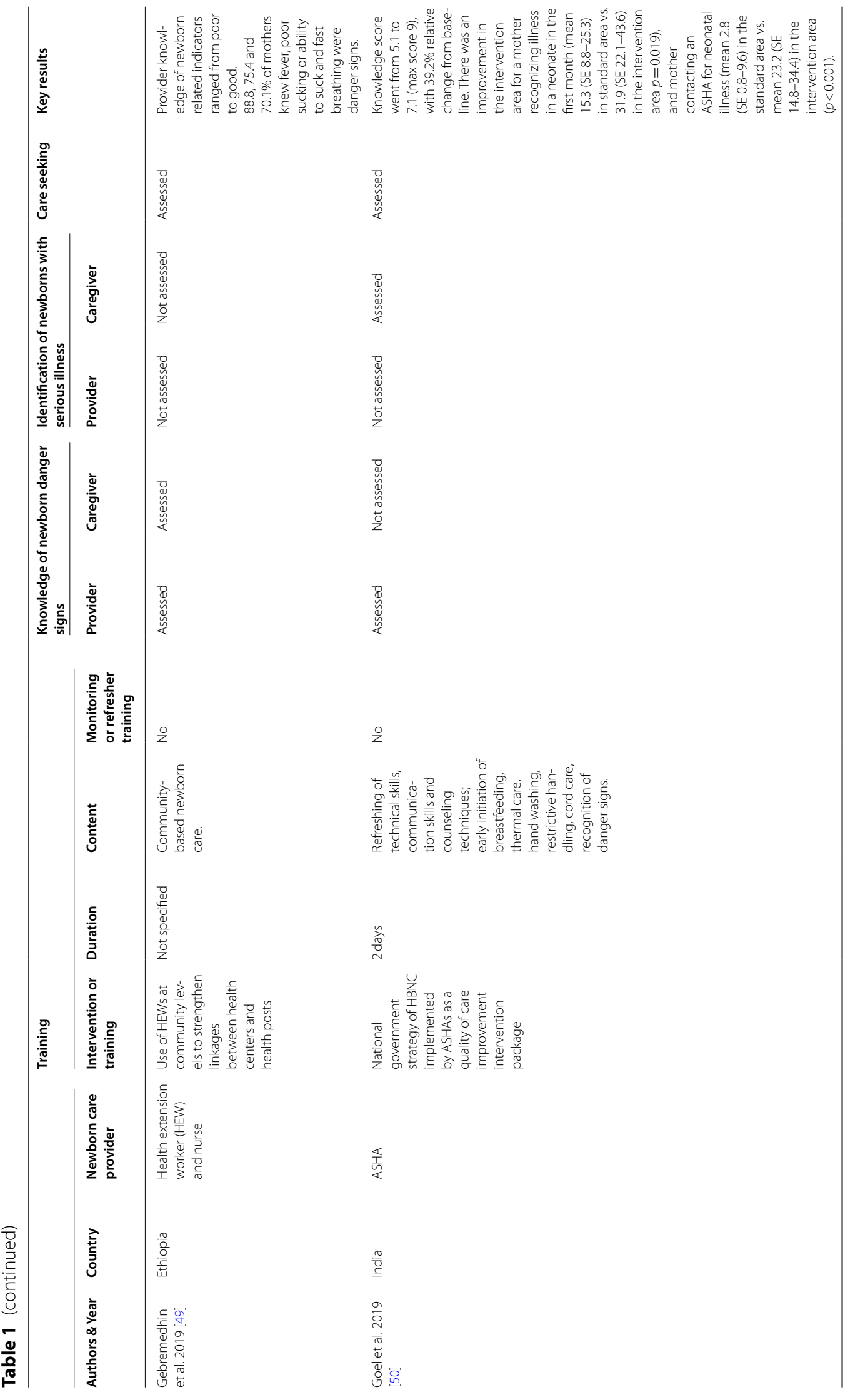




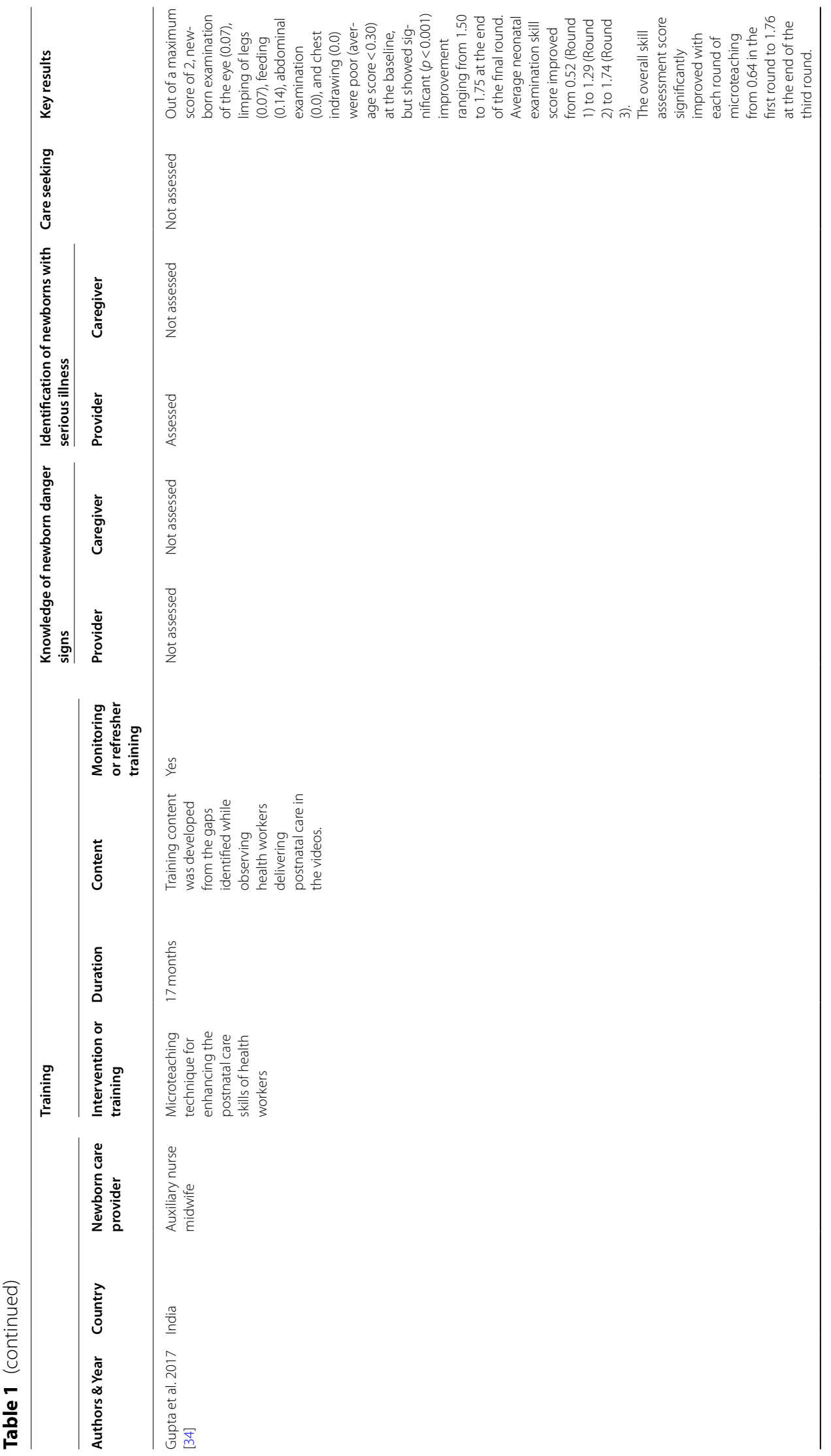




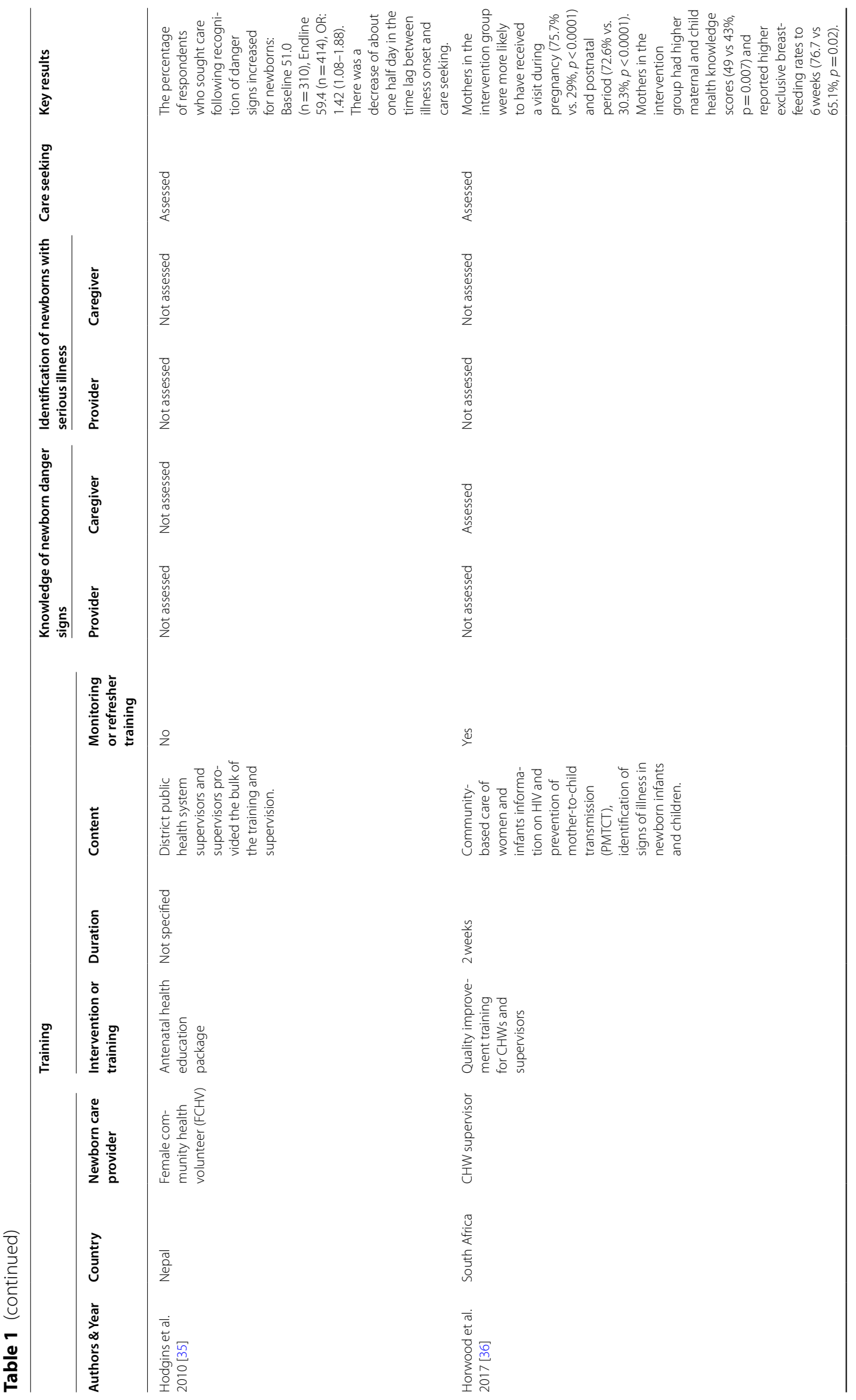




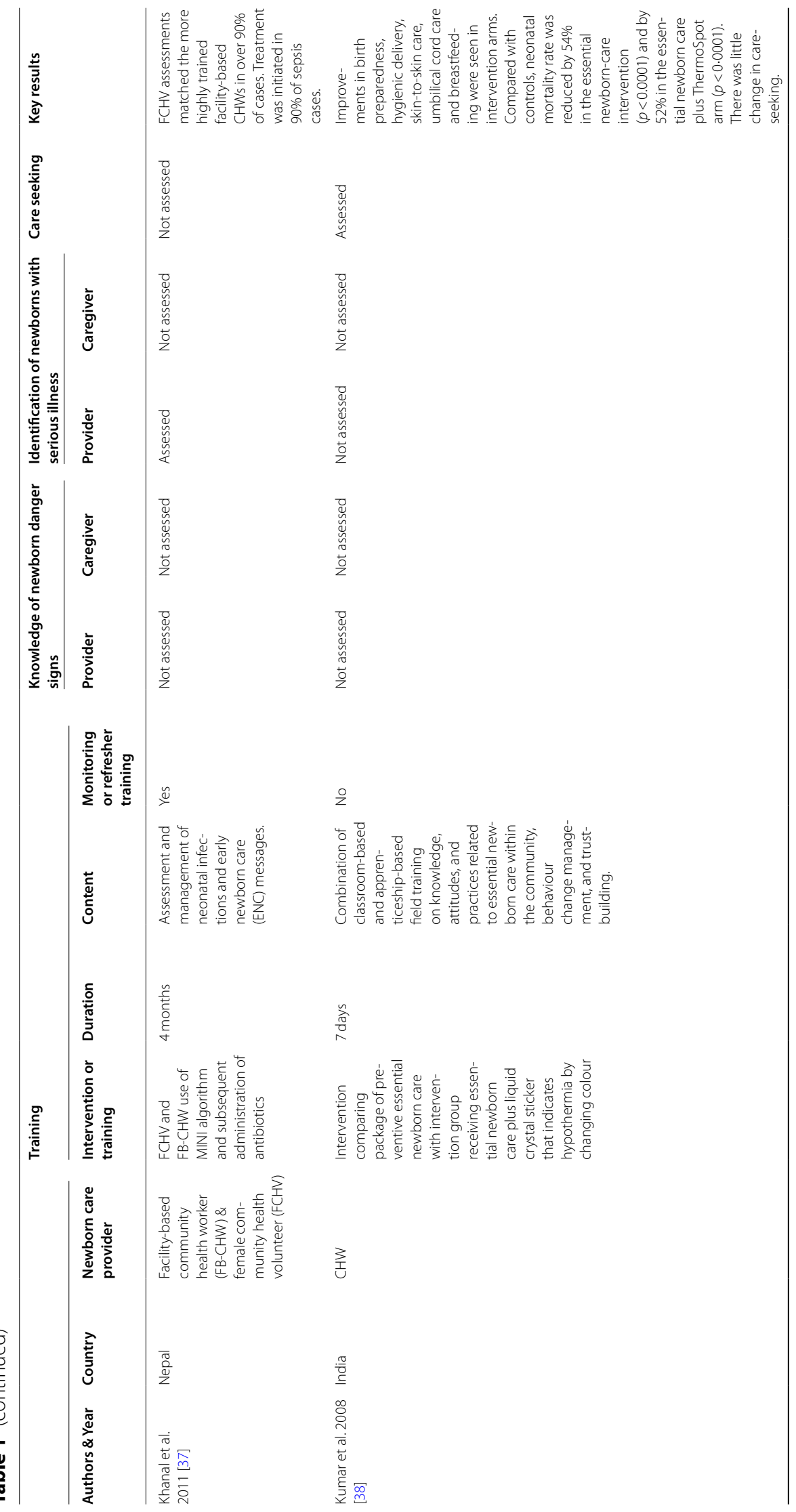




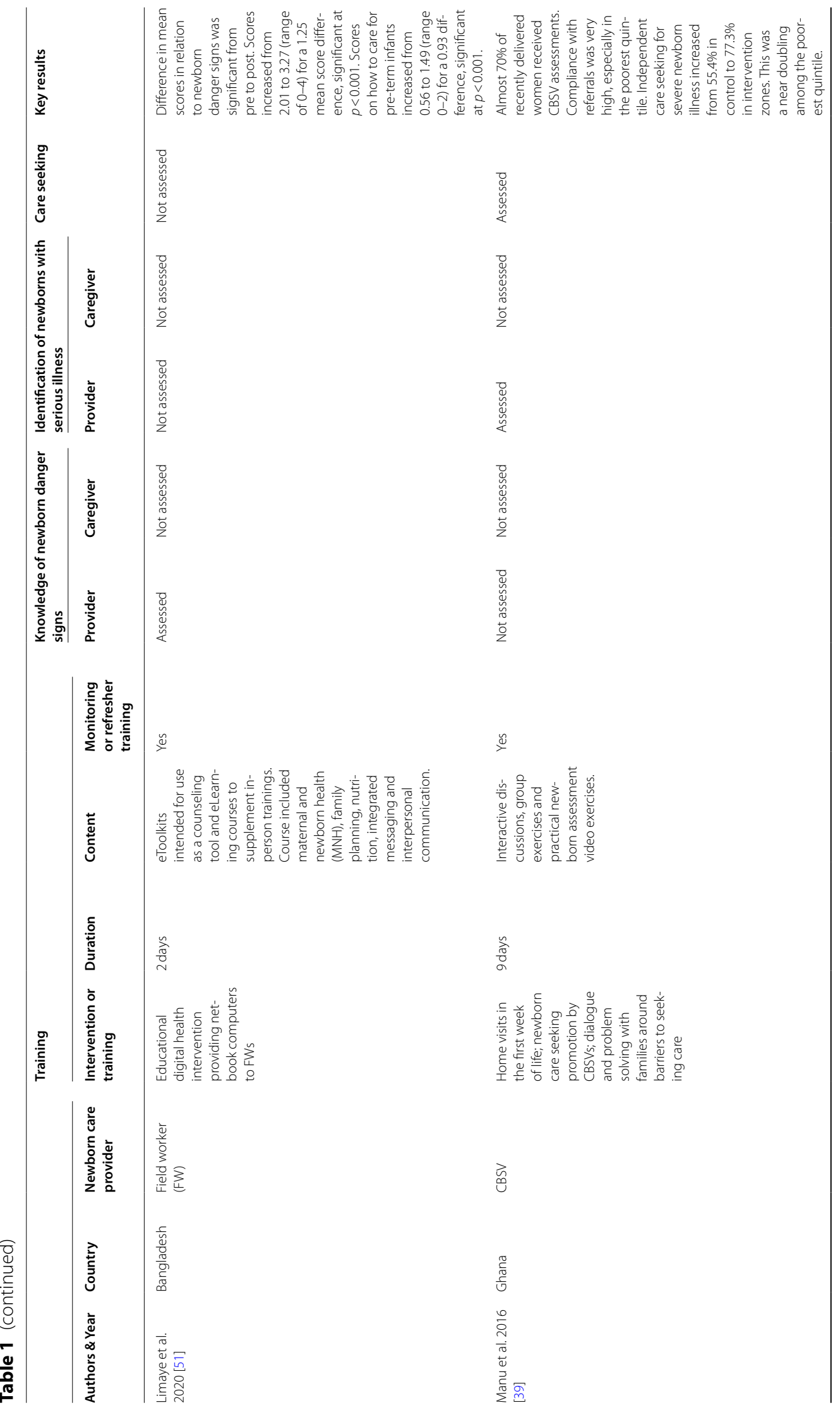




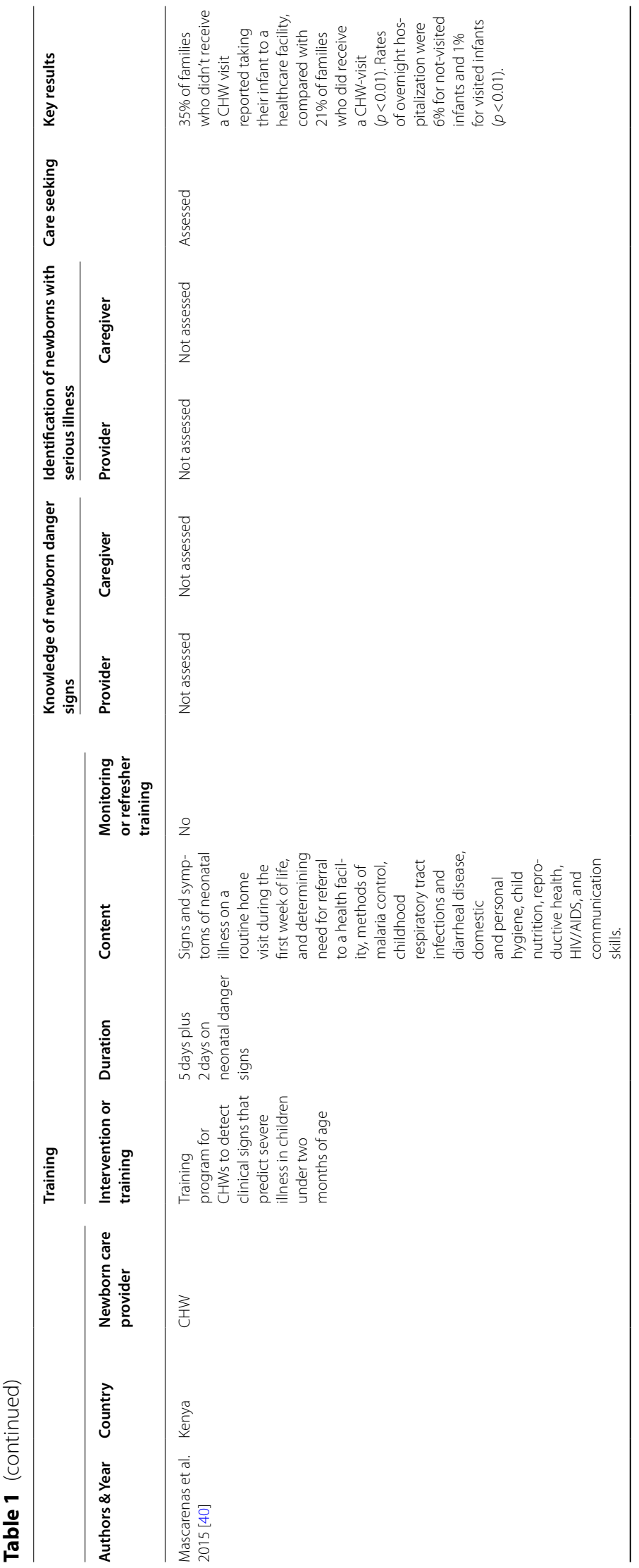




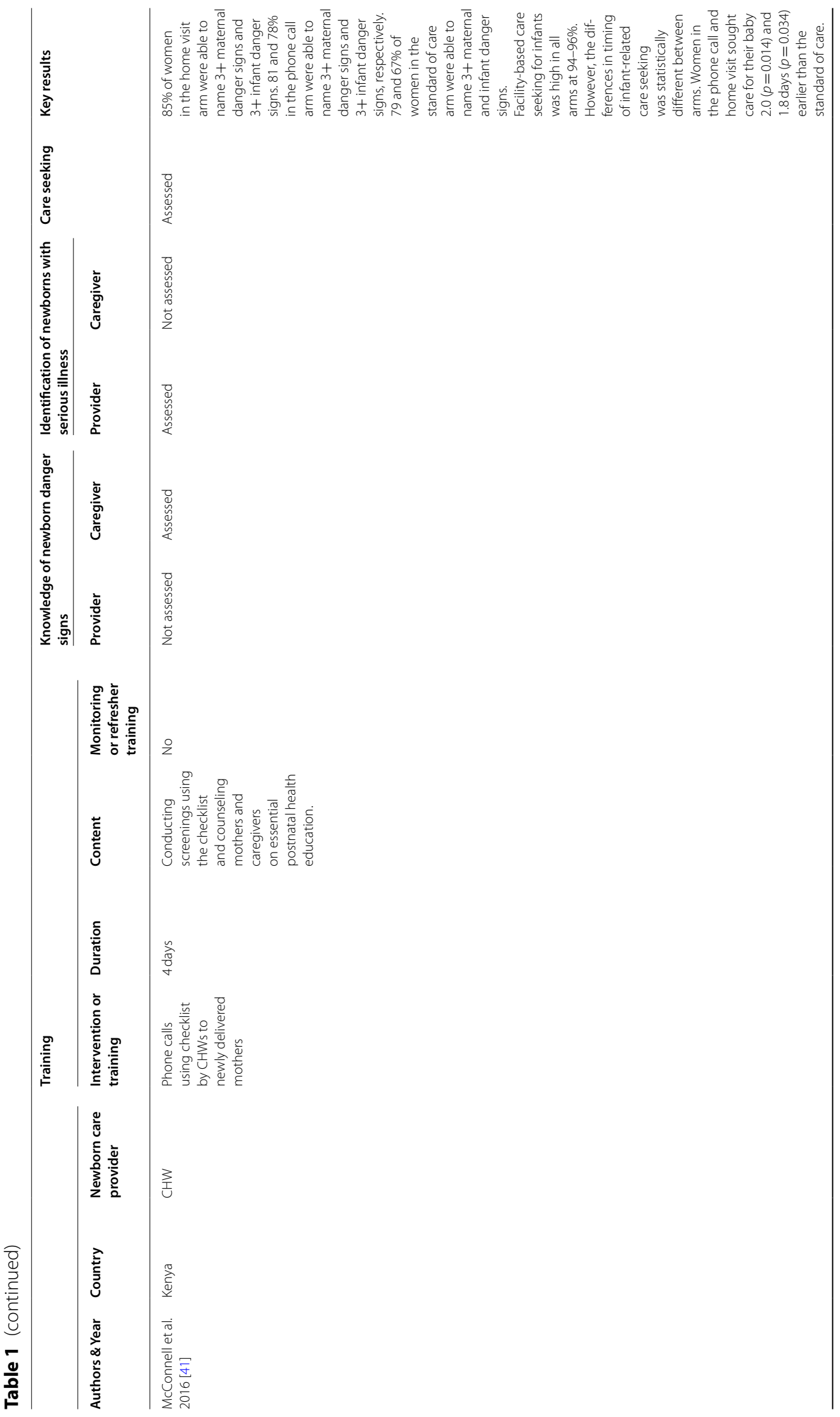




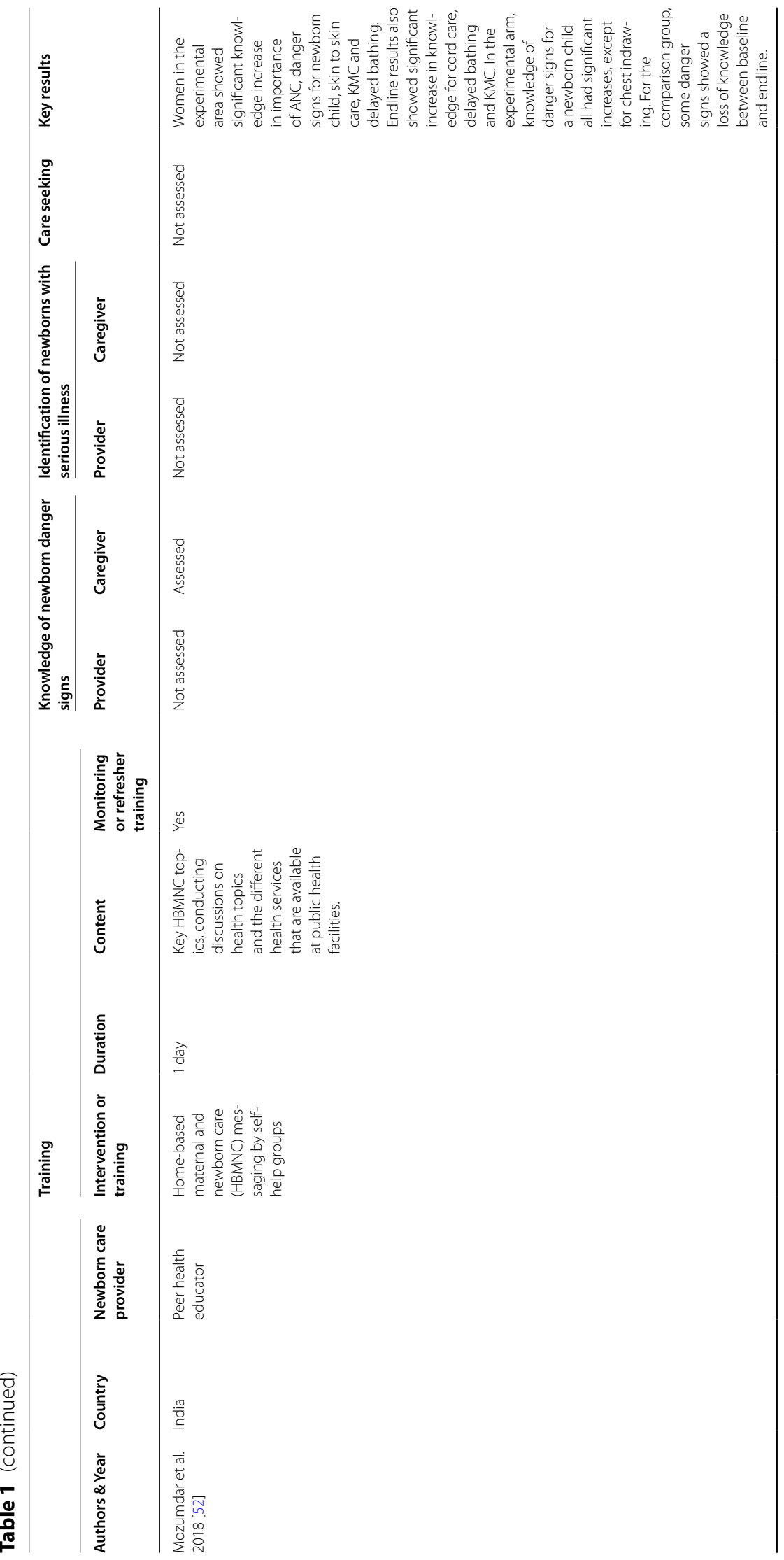




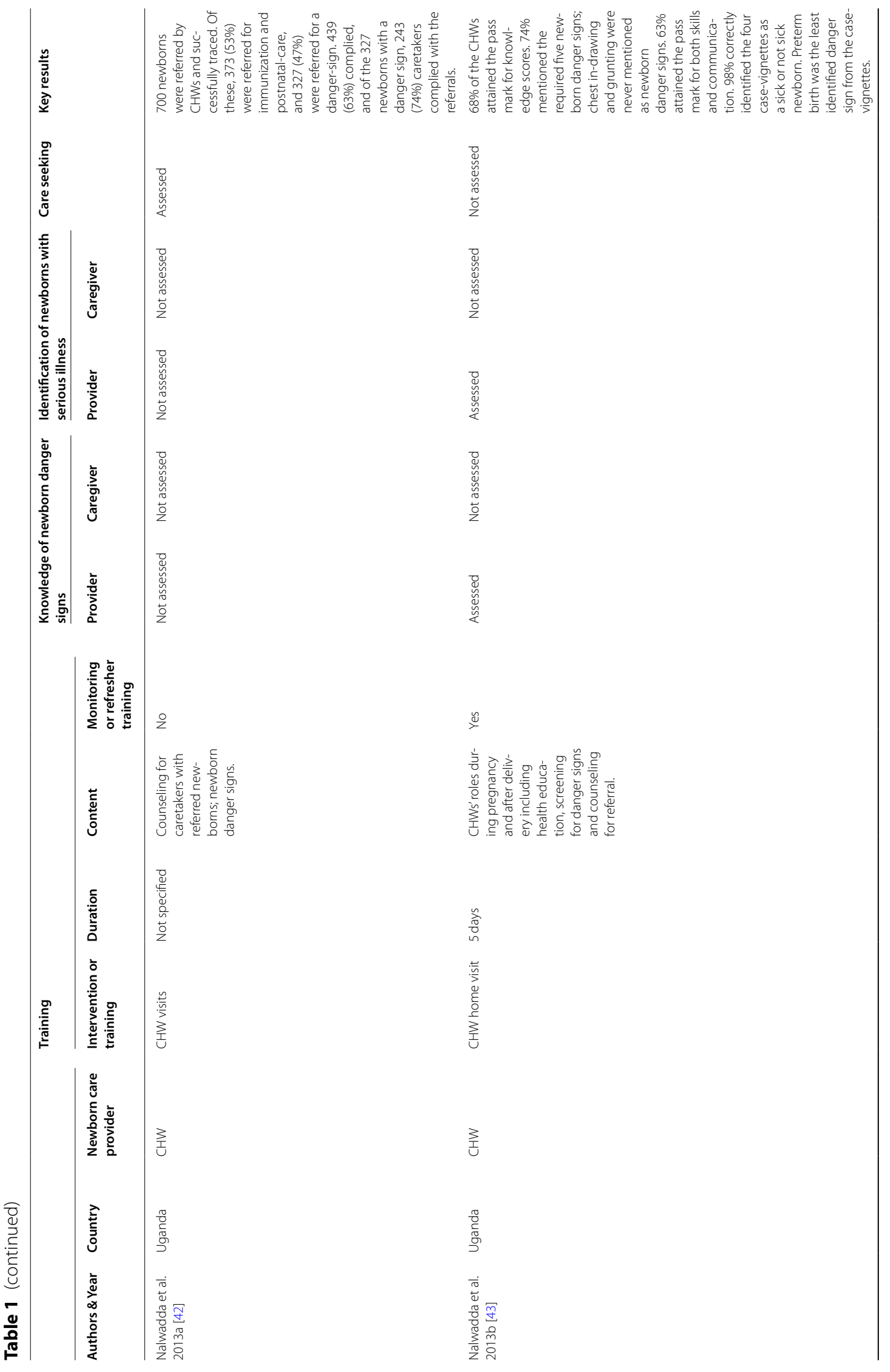




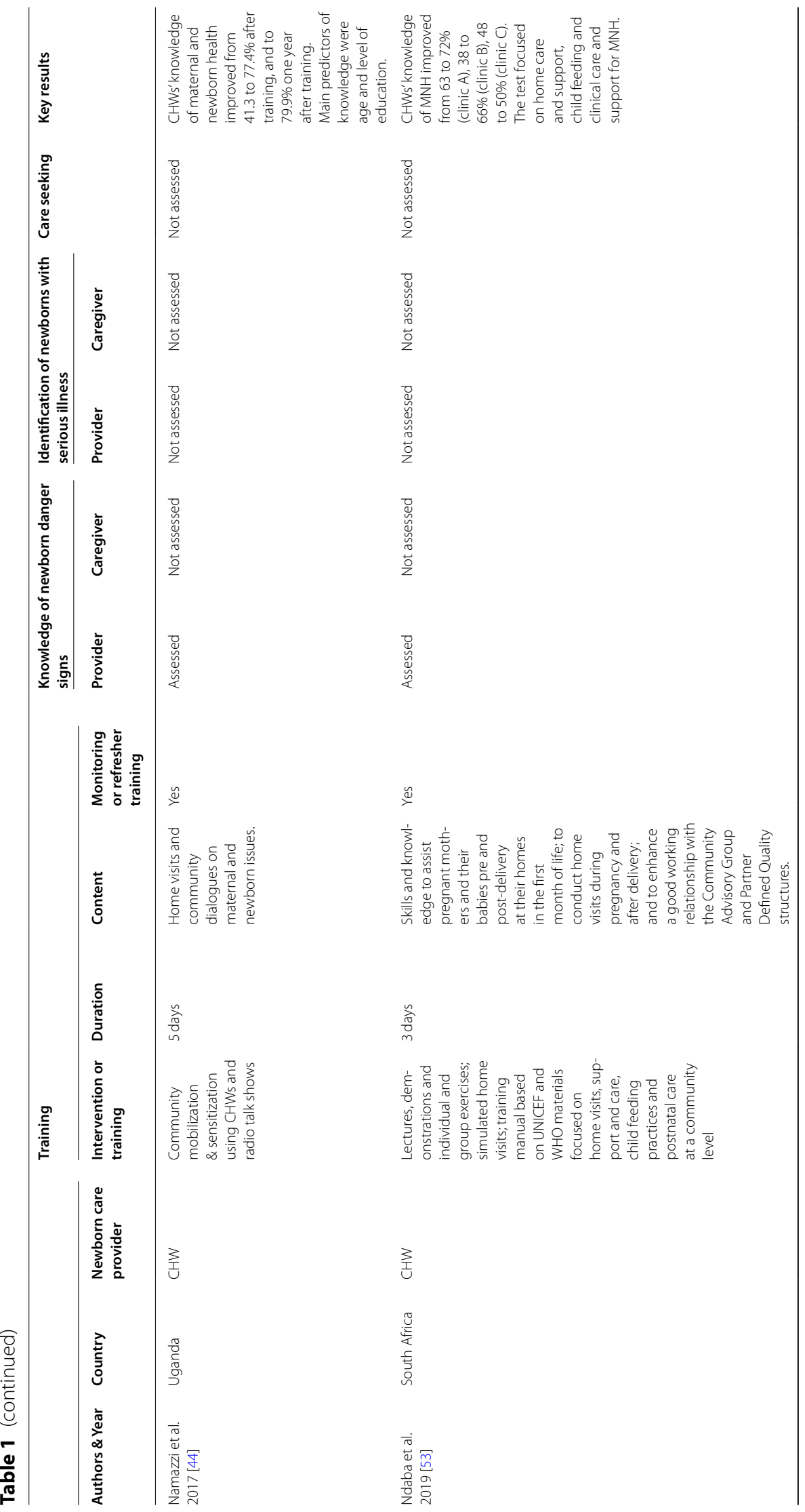




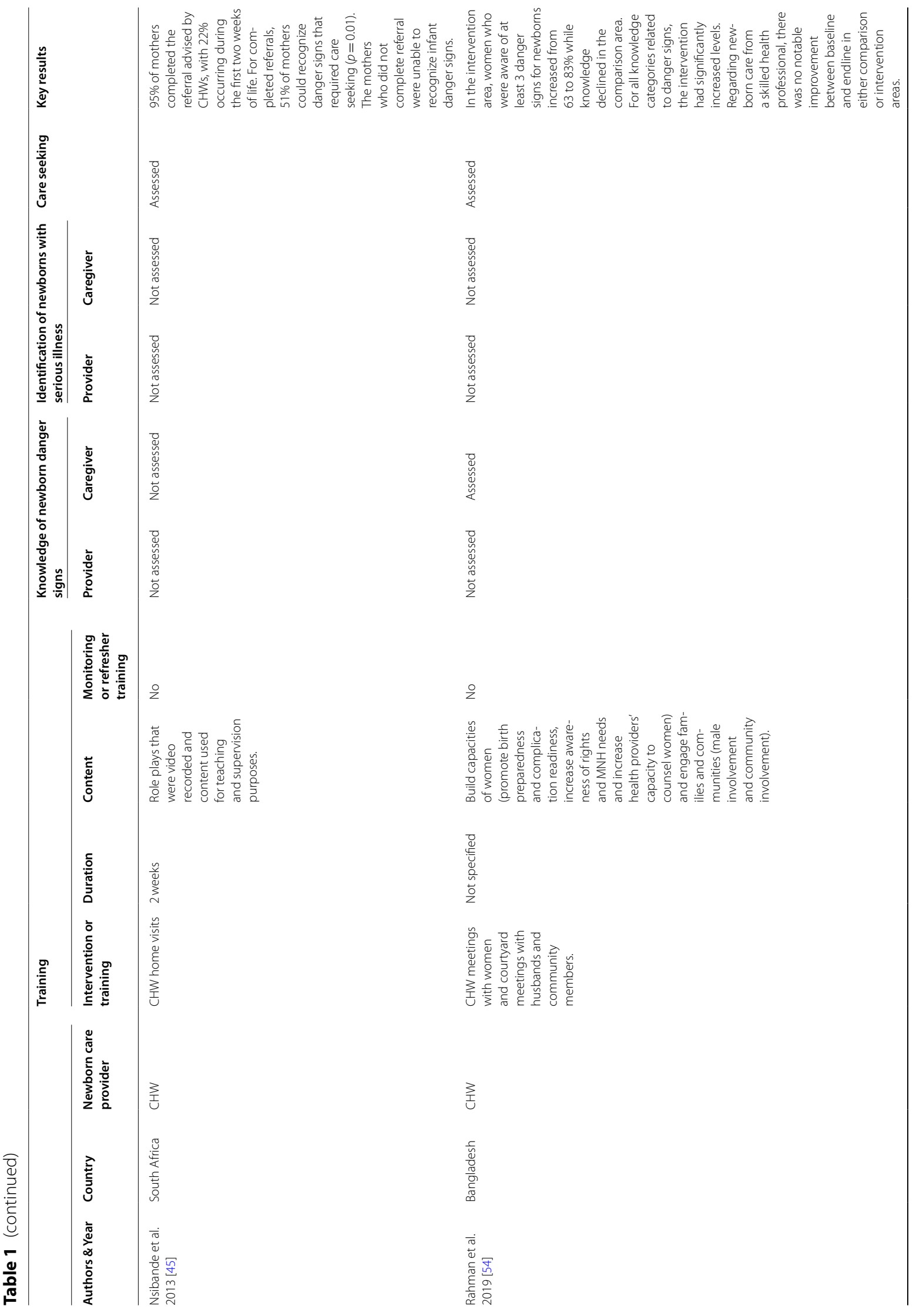




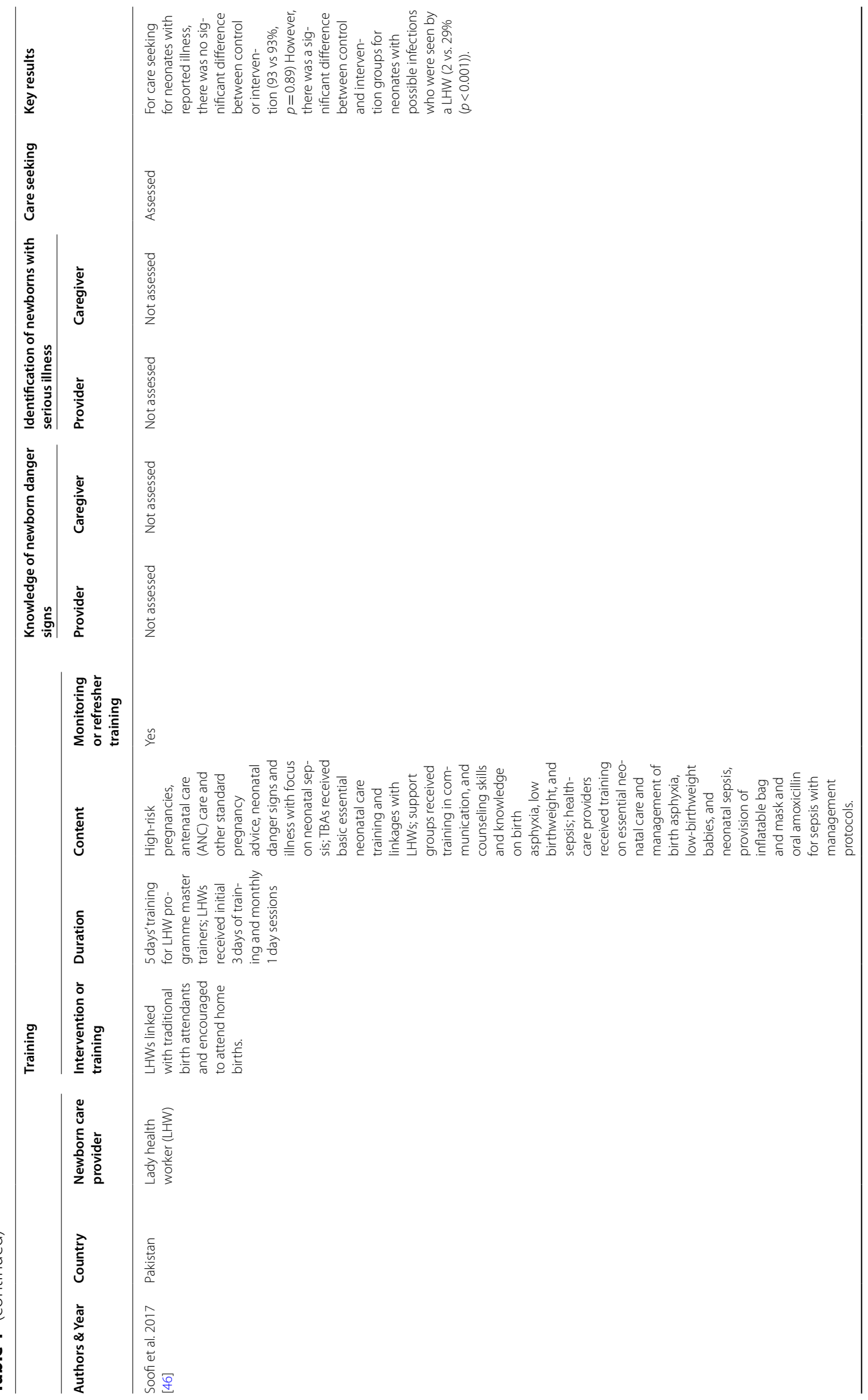




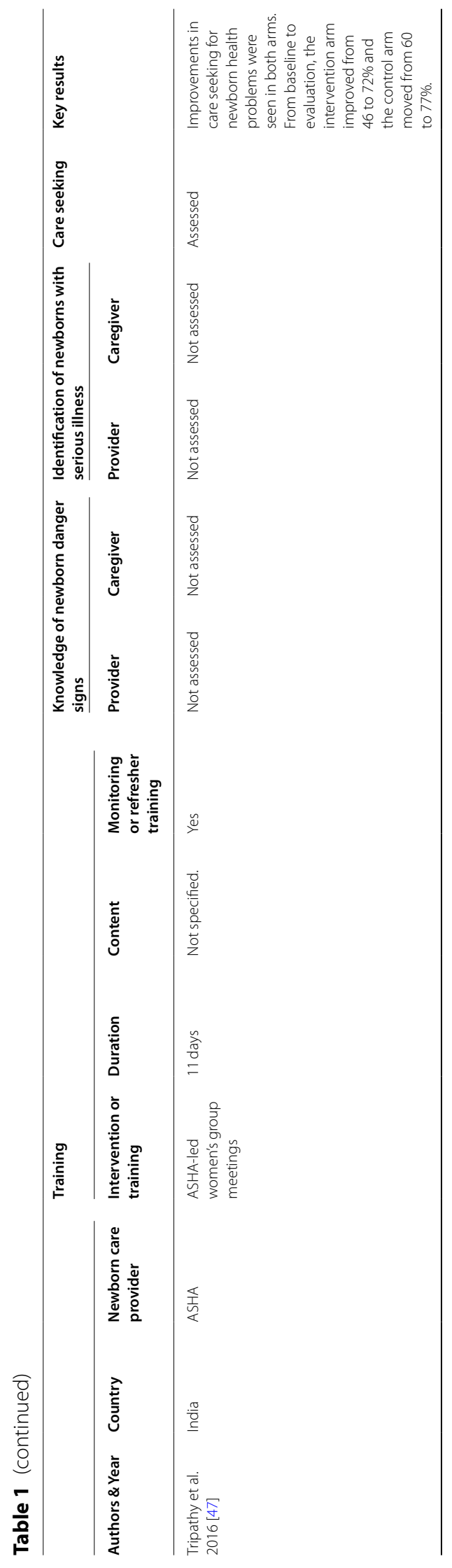




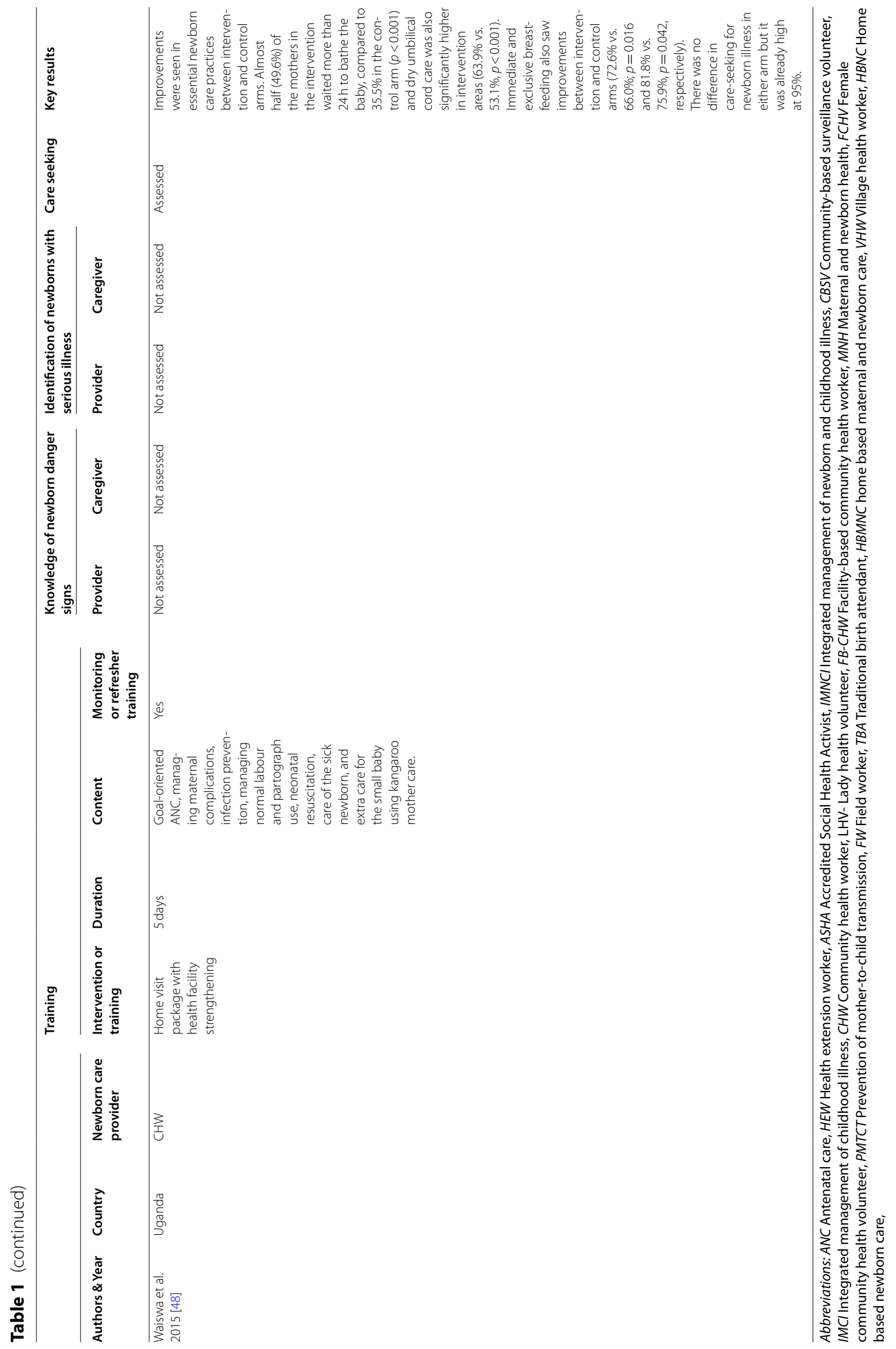




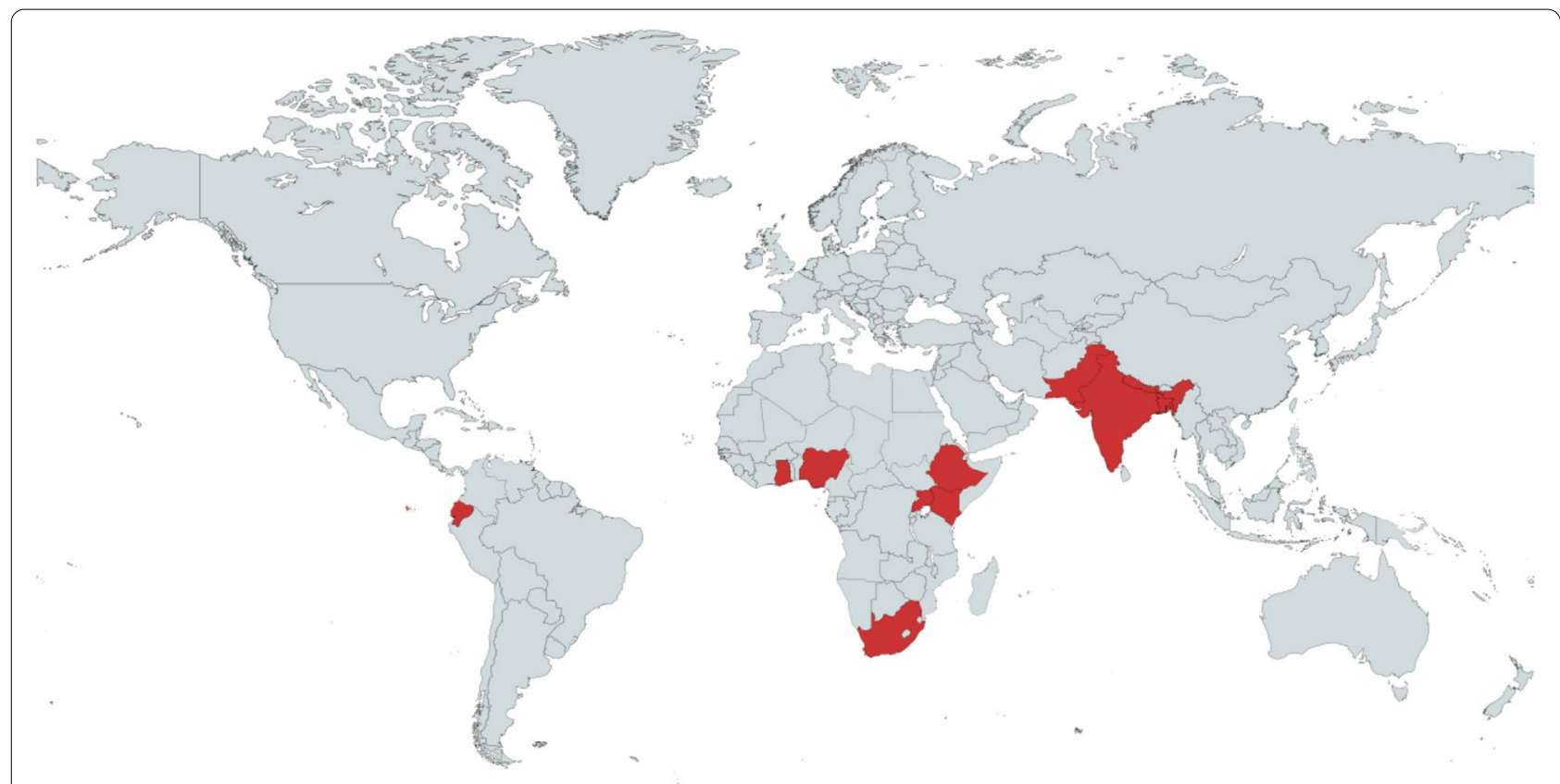

Fig. 2 Countries represented in included articles

[41]. The number and timing of home visits varied widely across studies. The number of home visits ranged from one to eight in the first 28 days of life. The scheduling of home visits had even greater variation, ranging from two antenatal and three postnatal home visits in the first week after birth,to one intervention having home visits on days $1,2,3,5,7,15,21,28$ with high-risk newborns also having visits on days $4,6,9,13$ and 18 . Overall, the most common number and schedule of visits was between three to five postnatal visits within the first 28 days, with visits on days 0,3 and 7, one visit at the beginning of the second week of life and one visit towards the end of the 28-day period.

\section{Training content}

The content of training varied but generally included history-taking, clinical assessment of mothers and newborns, identification of newborn danger signs, decision making for referral and facilitation of referral compliance, skills development for behaviour change communication, and data recording. Examples of newborn danger signs included: red umbilicus or cord with pus, newborn feeling hot or cold, failure to breastfeed, convulsions, rapid breathing, lack of body movement when stimulated, yellowing of the palms and soles, chest in-drawing and grunting [42]. Training and testing focused on visual assessments for newborn danger signs.

\section{Training methods}

Approaches to training included didactic teaching, demonstrations, role-plays, simulation exercises, practicing physical examination on newborns, group discussions, effective communication and educational messages and train-the-trainer models. Case vignettes were used as teaching tools and photographs and audiovisual materials were used as references for various neonatal danger signs. One study employed a technique called "microteaching" which involved several rounds of video recording with ongoing provision of feedback to continually improve newborn care provider performance [34].

\section{Provider effectiveness in knowledge and identification of newborn danger signs}

Six studies evaluated provider knowledge of newborn danger signs $[43,44,49-51,53]$. The results of all six studies suggested that training programs improved provider knowledge of newborn danger signs. For example, Namazzi et al. reported that knowledge of newborn danger signs and essential home-based newborn care improved following the training, with pre/post mean test scores of $41.3 \%$ versus 77.4 , and $79.9 \%$ one year later [44]. Thirteen studies included provider identification of newborns with serious illness as an outcome of interest [20, 22-25, 28, 30, 31, 34, 37, 39, 41, 43]. Overall, when comparing pre- and post-test results or baseline versus end line evaluations, CBHWs exhibited improved scores in identifying newborns with serious illness. Gupta et al. 


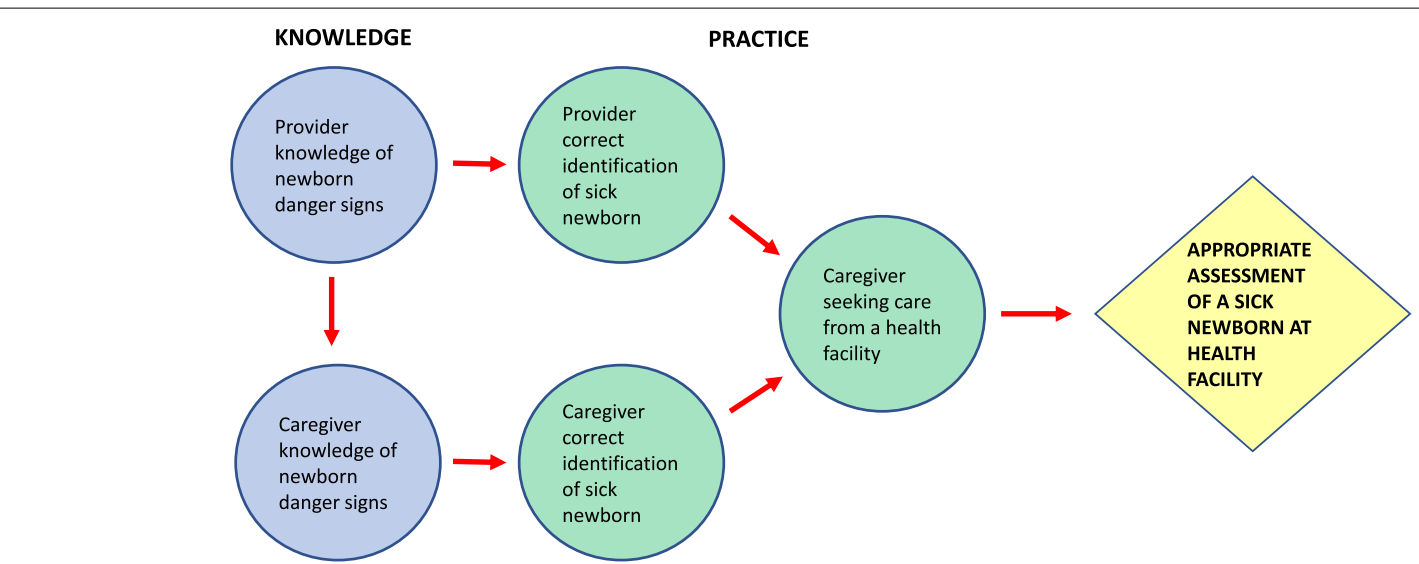

Fig. 3 Key outcomes to be measured in a newborn care training program to increase appropriate assessment of a sick newborn at a health facility

Table 2 Key components to consider in the design and implementation of a newborn care training program to achieve key outcomes

\begin{tabular}{|c|c|c|}
\hline Facilitators & Barriers & Components with unclear benefit \\
\hline $\begin{array}{l}\text { Sufficient duration of training } \\
\text { Refresher training and retraining } \\
\text { Supervision and on-the-job training } \\
\text { Community engagement }\end{array}$ & $\begin{array}{l}\text { Context-specific perceptions of newborn illness and } \\
\text { gender roles that may deter care-seeking from a health } \\
\text { facility }\end{array}$ & $\begin{array}{l}\text { Qualifications and experience prior to initiating } \\
\text { newborn care training } \\
\text { Newborn care provider incentives or remuneration }\end{array}$ \\
\hline
\end{tabular}

noted that there was significant improvement between baseline and the final round of assessments, with the skills assessment scores improving significantly after each round of microteaching. When CBHW assessments were compared with other more highly trained and experienced health cadres, the CBHW assessments obtained significant agreement with their counterparts [24, 25, 37]. Nalwadda et al. noted that, on average, seven of the 11 expected danger signs were identified with a median of 10 , but pre-term birth was the least commonly identified danger sign [43].

Key outcomes to be measured in an effective newborn care training program and intervention to improve identification of sick newborns and care-seeking from a health facility in LMICs

The included studies demonstrated that training newborn care providers can improve identification of sick newborns and care-seeking from a health facility in LMICs. Increasing appropriate assessment of a sick newborn and referral to a health facility requires measurement of five key interrelated outcomes that cover both knowledge and practice of newborn care providers and caregivers: 1) provider knowledge of newborn danger signs, 2) caregiver knowledge of newborn danger signs (through education from provider), 3) correct identification of sick newborn by provider, 4) correct identification of sick newborn by caregiver and 5) appropriate careseeking from a health facility (through compliance with provider referral or care-seeking from caregivers themselves) (Fig. 3). It is important for these key outcomes to be measured and evaluated at multiple time points during and after training and retraining.

\section{Key components to consider in the development of newborn care training programs to achieve key outcomes}

The key components to consider in the design and implementation of a newborn care training program to achieve key outcomes are summarized in Table 2 as facilitators, barriers and components with unclear benefit.

\section{Facilitators \\ Sufficient duration of training}

The median training duration was 39 days with a wide range among studies of four days to 17 months. One study showed intermediate ASHA to post-graduate female investigator agreement on the need for further assessment of infants (kappa 0.48, $P=<0.001$ ) [31]. Disagreement occurred for skin pustules, breastfeeding difficulty, incessant crying and infrequent newborn urination [31]. Compared to other studies, this study had a relatively short duration of training of five days. Three studies showed no difference in appropriate care-seeking 
by a caregiver between baseline and end line or between intervention and control groups [46-48]. Of note, these studies had relatively short training durations of three to 11 days.

\section{Refresher training and retraining}

Two studies assessed newborn care provider knowledge of newborn danger signs and both were conducted in Uganda [42, 44]. Nalwadda et al. evaluated CHWs 25 months after initial training and showed that almost all of the CHWs (56 out of 57, 98\%) correctly identified all the prompted newborn danger signs in case-vignettes [42]. Namazzi et al. showed that CHW knowledge of newborn danger signs improved markedly from 20.8 to 85.5\% following training [44]. However, after one year, the knowledge of three newborn danger signs dropped to $58.9 \%$ [44]. The duration of initial training in both studies was five days. Of note, in the study by Nalwadda et al., the CHWs met with their supervisors and were directly observed on a monthly basis following training to reinforce knowledge and skills. In another study, microteaching, that is, longitudinal video-recording of $\mathrm{CHW}$ patient encounters and providing regular feedback on strengths and weaknesses, led to improved newborn care provider ability to identify sick newborns over time [34]. The study by Namazzi et al. did not specify any refresher training.

Six studies showed that various newborn care providers including CBSVs, VHWs, CHWs and FCHVs were able to correctly classify sick newborns at home visits with high inter-rater agreement when compared to a gold standard (e.g., physicians, a computer algorithm, facilitybased CHWs) [20, 22-24, 28, 30]. Common themes in the training programs of these studies included interactive simulated newborn assessment video exercises, behaviour change communication and counselling and repeated assessment and retraining until performance was deemed satisfactory.

\section{Supervision and on-the-job training}

Nine studies included supervision and on-the-job training as part of CBHW training programs [20, 22-26, 39, $43,44]$. In all of these studies, the CBHWs were provided with direct supportive supervision at regular intervals. These intervals ranged from two days per month during which a supervisor accompanied the CBHW to drop-in visits by the district supervisor once per month. Where there was supportive supervision, feedback was provided immediately at the time of observation, in addition to regularly scheduled meetings with larger groups of CBHWs where shared challenges could be discussed and solutions developed as a group. In most studies, the supervisors were within the community health network. In the study by Namazzi et al., the supervisors were "super CHWs" who conducted observed supervision during home visits and facilitated regular meetings with CHWs, supervisors and district health management teams [44]. In four studies [20, 22, 23, 39], supervisors also ensured that supplies needed for CBHW home visits were maintained while observing and participating in home visits. Seven of the nine studies that included supervision or on-the-job training evaluated provider identification of newborn danger signs [20, 22-24, 39, 43, 44]. Results from these studies suggested that CBHWs were able to accurately assess newborns for danger signs. By contrast, in the study by Das et al., which did not mention supervision or on-the-job training, ASHAs failed to assess many critical newborn danger signs and there was poor agreement between ASHA and trained postgraduate female investigator assessments of illness severity (kappa $=0.23, P=0.01$ ) [31]. Based on these results, Das et al. highlighted the importance of ongoing supportive supervision to ensure CBHWs' long-term retention of illness assessment skills [31].

\section{Community engagement}

Eleven studies assessed caregiver knowledge of newborn danger signs and all showed significant improvements in this outcome in post-intervention groups compared to pre-intervention groups and in intervention groups compared to control groups [21, 27, 29, 32, 33, 36, 41, $49,50,52,54]$. Among these studies, integration of newborn care training and interventions into the community through community engagement was an important theme. In addition to providers teaching caregivers how to recognize newborn danger signs, one study included a weekly radio program providing information on danger signs, healthy behaviours and seeking professional care [27], one study utilized CV community outreach and engagement [32] and another study utilized mobile phone contacts [41]. Of note, CV community outreach and engagement and mobile phone $\mathrm{CHW}$ contacts individually performed similarly to home visits and led to significant improvement in caregiver knowledge of danger signs compared to the control $[32,41]$.

\section{Barriers \\ Contextual factors that may deter care-seeking}

Seventeen studies showed that newborn care provider training and home visits improved appropriate care-seeking from a health facility by a caregiver at end line compared to baseline or in intervention versus control groups $[20-23,26,27,29,35,36,38-41,45,49,50]$. Of the studies reporting poor or no difference in care-seeking behaviour, none incorporated consideration of potential barriers to care-seeking within their training and interventions. In one study in India, attribution of newborn 
illness to "evil eye" or "witchcraft" deterred care-seeking by a caregiver [21]. Conversely, the studies reporting improved care-seeking included innovative methods for increasing community acceptance of -newborn care provision and compliance with provider suggestions such as eliciting perceptions of newborn illness in the community through meetings with community leaders [20], a formal referral card system [26], facilitating transport [26, 29] and a weekly radio program that broadcasted information about healthy postnatal behaviours, newborn danger signs and seeking professional care [27].

Perceptions of gender roles are also an important consideration in community-based newborn care. One study in eastern Uganda highlighted that engaging husbands to support their wives in newborn care was challenging due to a perception that caregiver information on newborn care was designed for women [44]. However, community dialogue meetings led to increasing involvement of men in supporting their wives including saving funds for newborn care and emergencies [44]. Another study in rural Bangladesh included an intervention that specifically targeted husbands and aimed to increase their involvement in newborn care. CBHWs conducted meetings during which they discussed the roles and responsibilities of men in newborn care with the goal of destigmatizing men's involvement in newborn care [54]. This study demonstrated a significant increase in awareness of danger signs during pregnancy, childbirth and following childbirth among women and their husbands [54].

\section{Components with unclear benefit Qualifications and experience prior to initiating newborn care training}

Newborn care providers' level of education and competencies prior to initiating training varied widely among studies. Years of school education ranged from at least primary education to a minimum requirement of grade 12 education. In most studies, the minimum required education was at the primary level, with some requiring additional years at the secondary level. Most studies did not mention years of field experience for given CBHW cadres. In one study, CBSV experience ranged from eight months to 25 years with a mean of seven years [34]. Another study stated that $96 \%$ of the CHWs had worked for more than five years with few $(3.7 \%)$ having formal employment [44]. No particular descriptive association emerged between CBHW cadre education and key outcomes. One study in which $90 \%$ of CBSVs had at least primary education showed that CBSV assessments and referral decisions for sick newborns achieved excellent agreement with supervisors, suggesting that accurate newborn care provider identification of sick newborns is possible with providers who have at least primary education [20].

\section{Newborn care provider incentives or remuneration}

Incentives and remuneration for newborn care providers varied widely. Some studies specifically stated that no monetary incentives were offered while others included both monetary and non-monetary incentives. Examples of non-monetary incentives included T-shirts, working materials, briefcases and certificates following training. No clear descriptive association between incentives and key outcomes emerged. One study found through qualitative interviews that incentives were important motivators for CHWs and helped to minimize the dropout rate (3.6\%) [44]. At the same time, another study that specified no cash incentives demonstrated high agreement between FCHV identification of sick newborns compared to the more highly trained facility-based CHWs [37].

\section{Discussion}

This review identified 35 articles detailing 28 studies that evaluated CBHW newborn care providers' ability to recognize sick newborns and improve care-seeking for sick newborns from a health facility in LMICs. Most studies reported that newborn care training and provision can be effective in improving identification of sick newborns and care-seeking from a health facility in diverse LMIC settings where resources are limited and rates of neonatal mortality are high. Key interrelated outcomes that should be measured in an effective newborn care training program include, but are not limited to, high newborn care provider and caregiver knowledge of newborn danger signs, correct identification of sick newborns by providers and caregivers and appropriate care-seeking either through caregiver referral compliance or caregivers themselves seeking care for their newborns based on their knowledge and ability to correctly identify newborn danger signs. Although these outcomes have been identified as important for effective newborn care programs, there is limited understanding regarding the associations between these outcomes and their relative impact on reducing neonatal morbidity and mortality. For example, there is a need to further investigate whether caregiver knowledge of newborn danger signs is associated with improved care seeking. Important components to consider when designing and implementing a newborn care training program to achieve key outcomes were extracted. Facilitators included sufficient duration of training, refresher training and retraining, supervision and on-the-job training and community engagement. Barriers included context-specific understanding of newborn illness and gender roles that may 
deter care-seeking. Components with unclear benefit included qualifications and experience prior to newborn care training and incentives and remuneration. The studies in this review evaluated key outcomes individually; however, a next step would be to investigate how the components correlate to achieve the desired outcome of improved newborn health.

Duration of training varied widely but less than 11 days of training generally led to poorer outcomes compared to training in the range of weeks to months. The potential benefit of training duration longer than 11 days is important to consider given current WHO recommendations of three to six days for CHW training courses in newborn care [55]. Sufficient duration of training is needed to ensure that newborn care providers are confident in their abilities and that communities, in turn, trust and accept the services of newborn care providers.

Although the ability of newborn care providers to identify danger signs in newborns was generally positive, one study showed a significant decline in provider knowledge of newborn danger signs at one year post-training [44] and another cross-sectional study that did not specify the exact timing of evaluation post-training showed intermediate agreement between ASHAs and postgraduate female investigators regarding identification of sick newborns [31]. This illustrates the importance of routine and periodic feedback and refresher training of newborn care providers in order to maintain their skills in newborn assessment. Evidence of decline in provider knowledge of newborn danger signs at one-year post-training [44] suggests that refresher training should potentially occur earlier than one year. High knowledge retention was demonstrated with monthly retraining by supervisors [42], however, this frequency of retraining may not be practically achievable outside of research settings given limited resources. The optimal timing of refresher training should be further studied.

Similar to refresher training, supervision and on-thejob training were also shown to be essential components of newborn care training programs to reinforce skills and ensure and maintain quality newborn care. Supervision strategies ranged from direct observation to large $\mathrm{CBHW}$ group meetings to troubleshoot challenges. Further research is needed on the effects of various supervision strategies on CBHW performance.

Three studies showed no difference between baseline and end line or between intervention and control groups regarding care-seeking from a health facility by a caregiver for a sick newborn. Context-specific perceptions attributing newborn illness to 'evil eye' or 'witchcraft' deterred caregivers from seeking care from a health facility and perceptions that newborn care information was designed for women deterred the involvement of men in supporting their wives in newborn care. Therefore, more emphasis on developing skills for behaviour change communication and counselling to educate regarding context-specific perceptions of newborn illness and gender roles that may deter care-seeking from a health facility is critical. Beyond simply educating newborn care providers and caregivers about newborn danger signs, community leaders and members need to be actively involved in designing training and interventions in order for the intervention to be trusted, well-received and effective in a given country's specific socio-cultural context.

Related to culturally-sensitive care, another critical CBHW training component is respectful and dignified care. None of the included studies specified details related to the incorporation of respectful care into training programs. However, given the increasing evidence of disrespect, abuse, mistreatment and stigmatization of newborns [56], future CBHW newborn care training program development should ensure that respectful newborn care provision is taught, evaluated and practiced.

One included study evaluated TBA performance in identifying newborns with danger signs [27]. It is important to acknowledge that although TBAs met our definition of a CBHW, ongoing controversy exists regarding their role in maternal and newborn care including reports of inappropriate and outdated newborn care practices [57]. At the same time, TBAs have also been shown to have a positive role in bridging the relationships between the community and local health facilities $[57,58]$. Future newborn care training program development must ensure careful consideration of re-education for TBAs and other CBHWs while acknowledging their potentially important role in health facility referrals in specific cultural contexts and settings.

The importance of prior education and experience and of the presence of incentives and remuneration in improving key outcomes is likely context-specific. Training interventions, and those designing and implementing them, should account for factors that would affect a newborn care provider's clinical abilities such as educational background, previous training and medical experience, status in the community and remuneration. For example, an ASHA in India is the first point of contact for most communities for primary care and maternal and child health issues and needs to fulfil the educational criteria of being literate with "preference in selection to those who are qualified up to 10 standard ... this may be relaxed only if no suitable person with this qualification is available" [59]. The ASHA is not entitled to a salary, but rather receives performancebased incentives depending on the support provided. The potentially diverse education, qualifications and clinical experience of newborn care providers both 
within and between countries should be considered when determining the duration, content and follow-up in the provision of newborn care training. A broad or heterogeneous definition of what constitutes a $\mathrm{CHW}$ or other newborn care provider type may affect planning of interventions particularly with regard to duration and extent of training in a given country's specific context.

Beyond improving provider and caregiver knowledge of newborn danger signs, identification of sick newborns and appropriate care-seeking through a newborn care training program, it is also important to ensure that transport to a health facility is quickly accessible once the decision to seek care has been made. Studies in LMICs have shown that transport-related delays are a significant contributor to neonatal deaths $[8,9]$. In several studies included in this scoping review, newborn care providers facilitated transport to health facilities $[20,29,30]$ or a community emergency transport system was established $[26,32,33]$. Functioning referral systems from community to facility are necessary but not sufficient to ensure improved neonatal outcomes. While an effective referral system involving identification of sick newborns and appropriate care-seeking is critical to reduce neonatal mortality, it must be considered as part of a broader continuum of newborn care that includes other important interventions such as breastfeeding support, kangaroo mother care, chlorhexidine umbilical cord cleansing, antibiotic treatment for infections, and full supportive facility care [60]. These interventions should also be taught and knowledge tested in training programs. In addition to functioning referral systems, other critical interconnected system requirements are needed to improve the quality of newborn care including evidencebased practices, actionable information systems, effective communication with patients and families, respect and preservation of dignity, emotional support, a competent and motivated workforce and availability of essential physical resources [61, 62]. As increasing investments are directed at improving inpatient care of small and sick newborns [63], robust training of CBHWs to improve community-based identification of sick newborns and care-seeking from a health facility is needed to ensure appropriate and timely assessment of sick newborns requiring inpatient care.

This scoping review narratively described key components to be considered in designing an effective CBHW newborn care training program to improve identification of sick newborns and appropriate care-seeking. These components align with recommendations from the WHO 2018 guideline on health policy and system support to optimize community health worker programs which include supportive supervision, remuneration and community engagement [64]. Future research in CBHW newborn care training should directly assess the relative impact of various durations of training, timing of refresher training, combinations of supportive supervision strategies, community engagement strategies, mitigation of local perceptions of illness and gender roles that may deter care-seeking, pre-training qualifications and incentives and remuneration on the key outcomes to improve CBHW identification of sick newborns and care-seeking from a health facility.

\section{Limitations}

This review had several limitations. First, as is the case with scoping review methodology, we did not assess the quality of selected studies. The overall high proportion of improved outcomes could be attributed to publication bias. However, this review provides an overview of the available evidence for the effectiveness of newborn care providers in the identification and referral of sick newborns upon which further interventions and strategies can be evaluated and implemented at scale. Second, the included studies only represented 11 countries across three subcontinents and many LMICs were not represented which limits the generalizability of our findings. Future development and implementation of newborn care provider training should be adapted to local cultural, socio-economic and political factors. Third, the time of publication of included articles varied widely with the earliest article published in 2005. Since that time, notable advancements have been made in the evidence base for newborn interventions. These include increased coverage of facility-based deliveries and deliveries attended by skilled health personnel [4], chlorhexidine umbilical cord cleansing, additional evidence supporting known beneficial interventions such as kangaroo mother care and antenatal steroids, outpatient injectable antibiotics for neonatal infections and innovation of equipment and training methods for neonatal resuscitation [3]. Our findings must be considered in the context of these advancements in newborn care. Although such innovations have likely reduced the proportion of sick neonates in community settings, community-based identification of sick newborns and care-seeking from a health facility remains an important priority to continue to reduce neonatal mortality. Finally, no authors of this review were from LMICs. Future research and training program development based on these findings should aim to include LMIC collaborators who could provide important national or local contextual insight.

\section{Conclusion}

Training newborn care providers to successfully identify sick newborns and improve care-seeking behaviour is an important contributor to the global goals of decreasing 
neonatal mortality and ending preventable deaths of newborns as outlined in the SDG3.2. High newborn care provider and caregiver knowledge of newborn danger signs, correct identification of sick newborns by providers and caregivers and appropriate care-seeking from a health facility are important outcomes to be measured when designing a newborn care training program to reduce neonatal morbidity and mortality. Facilitators to achieve these key outcomes include sufficient duration of training, regular refresher training, supervision and onthe-job training and community engagement. Barriers include local perceptions of newborn illness and gender roles that may deter care-seeking from a health facility. Components with unclear benefit include qualifications prior to training and incentives and remuneration. Training curriculum development must be culturallysensitive, respectful and grounded within specific local contexts. Our findings can inform the design of future CBHW newborn care training programs in LMICs. Further research is needed to determine the relative impact of the facilitators, barriers and components with unclear benefit on key outcomes and to investigate the associations between key outcomes and their relative impact on reducing neonatal morbidity and mortality.

\begin{abstract}
Abbreviations
ANM : Auxiliary nurse midwife; ASHA : Accredited Social Health Activist; CBHW: Community-based health worker; CBSV : Community-based surveillance volunteer; CHW : Community health worker; CV : Community volunteer; FCHV : Female community health volunteer; HEW : Health extension worker; LHW : Lady health worker; LMIC : Low- and middle-income country; MDG : Millennium Development Goal; PMTCT: Prevention of mother-to-child transmission; SDG : Sustainable Development Goal; TBA : Traditional birth attendant; VHW : Village health worker; WHO : World Health Organization.
\end{abstract}

\section{Supplementary Information}

The online version contains supplementary material available at https://doi. org/10.1186/s12884-021-04240-3.

Additional file 1. 1 PRISMA-SCR checklist. PRISMA-SCR checklist.

Additional file 2. Full electronic search strategy for Medline (Ovid). Full electronic search strategy for Medline (Ovid).

Additional file 3. Characteristics of studies on postnatal care providers in low-and middle-income countries (expanded). Expanded results table.

\section{Acknowledgements}

Not applicable.

\section{Authors' contributions}

AF - concept/design; review of articles; extraction and analysis of data; writing and critical revision. EH - review of articles; extraction and analysis of data; writing and critical revision. EdP -review of articles; critical revision. NA - acquisition of data; critical revision. LA - concept/design; critical revision. MC - concept/design; critical revision. All authors read and approved the final manuscript.

\section{Funding}

There were no sources of funding for this manuscript.
Availability of data and materials

The datasets used and/or analysed during the current study are available from the corresponding author on reasonable request.

\section{Declarations}

Ethics approval and consent to participate

Not applicable.

\section{Consent for publication}

Not applicable.

\section{Competing interests}

The authors declare that they have no competing interests.

\section{Author details}

${ }^{1}$ Hospital for Sick Children, Division of Paediatric Medicine, University of Toronto, 555 University Ave., Rm 10402, Black Wing, Toronto, Ontario M5G 1X8, Canada. ${ }^{2}$ Institute for Global Public Health, Rady Faculty of Health Sciences, University of Manitoba, R070 Med Rehab Bldg, 771 McDermot Avenue, Winnipeg, Manitoba R3E 0T6, Canada. ${ }^{3}$ Neil John Maclean Health Sciences Library, Rady Faculty of Health Sciences, University of Manitoba, 727 McDermot Avenue, Winnipeg, Manitoba R3E 0T6, Canada. ${ }^{4}$ Institute for Global Public Health, Department Of Obstetrics, Gynecology and Reproductive Sciences, Rady Faculty of Health Sciences, University of Manitoba, R070 Med Rehab Bldg, 771 McDermot Avenue, Winnipeg, Manitoba R3E 0T6, Canada. Institute for Global Public Health, Department of Pediatrics and Child Health, Medical Microbiology and Infectious Diseases, Community Health Sciences, Rady Faculty of Health Sciences, University of Manitoba, R070 Med Rehab Bldg, 771 McDermot Avenue, Winnipeg, Manitoba R3E 0T6, Canada.

Received: 7 April 2021 Accepted: 29 October 2021

Published online: 14 December 2021

\section{References}

1. UNICEF and partners in the UN Inter-Agency Group for Child Mortality Estimation. Levels and Trends in Child Mortality Report 2020: Estimates developed by the UN Inter-agency Group for Child Mortality Estimation: United Nations Children's Fund; 2020 [Available from: https://data. unicef.org/resources/levels-and-trends-in-child-mortality/.

2. Global, regional, national, and selected subnational levels of stillbirths, neonatal, infant, and under-5 mortality, 1980-2015: a systematic analysis for the Global Burden of Disease Study 2015. Lancet (London, England). 2016;388(10053):1725-74.

3. Bhutta ZA, Das JK, Bahl R, Lawn JE, Salam RA, Paul VK, et al. Can available interventions end preventable deaths in mothers, newborn babies, and stillbirths, and at what cost? Lancet (London, England). 2014;384(9940):347-70.

4. UNICEF. Maternal and Newborn Health: Delivery Care 2021 [Available from: https://data.unicef.org/topic/maternal-health/delivery-care/.

5. Kabugo D, Nakamura H, Magnusson B, Vaughan M, Niyonshaba B, Nakiganda C, et al. Mixed-method study to assess the feasibility, acceptability and early effectiveness of the Hospital to Home programme for follow-up of high-risk newborns in a rural district of Central Uganda: a study protocol. BMJ Open. 2021;11(3):e043773.

6. Hug L, Alexander M, You D, Alkema L. National, regional, and global levels and trends in neonatal mortality between 1990 and 2017, with scenariobased projections to 2030: a systematic analysis. Lancet Glob Health. 2019:7(6):e710-e20.

7. Sankar MJ, Natarajan CK, Das RR, Agarwal R, Chandrasekaran A, Paul VK. When do newborns die? A systematic review of timing of overall and cause-specific neonatal deaths in developing countries. J Perinatol. 2016;36(Suppl 1):S1-s11.

8. Waiswa P, Kallander K, Peterson S, Tomson G, Pariyo GW. Using the three delays model to understand why newborn babies die in eastern Uganda. Tropical Med Int Health. 2010;15(8):964-72. 
9. Upadhyay RP, Rai SK, Krishnan A. Using three delays model to understand the social factors responsible for neonatal deaths in rural Haryana, India. J Trop Pediatr. 2013;59(2):100-5.

10. Herbert HK, Lee AC, Chandran A, Rudan I, Baqui AH. Care seeking for neonatal illness in low- and middle-income countries: a systematic review. PLoS Med. 2012;9(3):e1001183.

11. World Health Organization. WHO recommendations on postnatal care of the mother and newborn. Geneva: World Health Organization; 2014. [Available from: https://apps.who.int/iris/bitstream/handle/10665/97603/ 9789241506649_eng.pdf? sequence $=1$

12. Gogia S, Sachdev HS. Home visits by community health workers to prevent neonatal deaths in developing countries: a systematic review. Bull World Health Organ. 2010;88(9):658-6b.

13. Lassi ZS, Middleton PF, Crowther C, Bhutta ZA. Interventions to Improve Neonatal Health and Later Survival: An Overview of Systematic Reviews. EBioMedicine. 2015;2(8):985-1000.

14. World Bank Country and Lending Groups. The World Bank; 2016. Available from: https://datahelpdesk.worldbank.org/knowledgebase/articles/ 906519-world-bank-country-and-lending-groups

15. Joanna Briggs Institute Reviewers'Manual: 2015 edition / Supplement. The University of Adelaide, Australia: The Joanna Briggs Institute; 2015. Available from: http://joannabriggs.org/assets/docs/sumari/ReviewersManual_Methodology-for-JBI-Scoping-Reviews_2015_v2.pdf.

16. Scott K, Beckham SW, Gross M, Pariyo G, Rao KD, Cometto G, et al. What do we know about community-based health worker programs? A systematic review of existing reviews on community health workers. Hum Resour Health. 2018:16(1):39.

17. Jeet G, Thakur JS, Prinja S, Singh M. Community health workers for noncommunicable diseases prevention and control in developing countries: Evidence and implications. PLoS One. 2017;12(7):e0180640.

18. WHO. WHO recommendations on newborn health: guidelines approved by the WHO Guidelines Review Committee. Geneva: World Health Organization; 2017. Available from: https://apps.who.int/iris/handle/ $10665 / 259269$

19. Clinical signs that predict severe illness in children under age 2 months: a multicentre study. Lancet. 2008;371 (9607):135-42.

20. Ansah Manu A, ten Asbroek A, Soremekun S, Gyan T, Weobong B, Tawiah-Agyemang C, et al. Evaluating the implementation of community volunteer assessment and referral of sick babies: lessons learned from the Ghana Newhints home visits cluster randomized controlled trial. Health Policy Plan. 2014;29:ii114-27.

21. Bang AT, Bang RA, Reddy HM, Deshmukh MD, Baitule SB. Reduced incidence of neonatal morbidities: effect of home-based neonatal care in rural Gadchiroli, India. J Perinatol: official journal of the California Perinatal Association. 2005;25:S51-61.

22. Bang AT, Bang RA, Stoll BJ, Baitule SB, Reddy HM, Deshmukh MD. Is home-based diagnosis and treatment of neonatal sepsis feasible and effective? Seven years of intervention in the Gadchiroli field trial (1996 to 2003). J Perinatol: official journal of the California Perinatal Association. 2005;25:562-71.

23. Bang AT, Baitule SB, Reddy HM, Deshmukh MD, Bang RA. Low birth weight and preterm neonates: can they be managed at home by mother and a trained village health worker? J Perinatol: official journal of the California Perinatal Association. 2005;25:S72-81.

24. Baqui AH, Arifeen SE, Rosen HE, Mannan I, Rahman SM, Al-Mahmud AB, et al. Community-based validation of assessment of newborn illnesses by trained community health workers in Sylhet district of Bangladesh. Tropical Med Int Health. 2009;14(12):1448-56.

25. Baqui AH, Arifeen SE, Williams EK, Ahmed S, Mannan I, Rahman SM, et al. Effectiveness of home-based management of newborn infections by community health workers in rural Bangladesh. Pediatr Infect Dis J. 2009;28(4):304-10.

26. Bari S, Mannan I, Rahman MA, Darmstadt GL, Serajil MHR, Baqui AH, et al. Trends in use of referral hospital services for care of sick newborns in a community-based intervention in Tangail District, Bangladesh. J Health Popul Nutr. 2006:24(4):519-29.

27. Broughton E, Hermida J, Hill K, Sloan N, Chavez M, Gonzalez D, et al. Evaluation of an Intervention to Improve Essential Obstetric and Newborn Care Access and Quality in Cotopaxi, Ecuador. Front Public Health. 2016:4:247.
28. Darmstadt GL, Baqui AH, Choi Y, Bari S, Rahman SM, Mannan I, et al. Validation of a clinical algorithm to identify neonates with severe illness during routine household visits in rural Bangladesh. Arch Dis Child. 2011;96(12):1140-6.

29. Darmstadt GL, Choi Y, Arifeen SE, Bari S, Rahman SM, Mannan I, et al, Evaluation of a cluster-randomized controlled trial of a package of community-based maternal and newborn interventions in Mirzapur, Bangladesh. PLoS One. 2010;5(3):e9696.

30. Darmstadt GL, Baqui AH, Choi Y, Bari S, Rahman SM, Mannan I, et al. Validation of community health workers'assessment of neonatal illness in rural Bangladesh. Bull World Health Organ. 2009;87(1):12-9.

31. Das E, Panwar DS, Fischer EA, Girdhari B, Carlough MC. Performance of accredited social health activists to provide home-based newborn care: a situational analysis. Indian Pediatr. 2014;51(2):142-4.

32. Findley SE, Uwemedimo OT, Doctor HV, Green C, Adamu F, Afenyadu GY. Comparison of high- versus low-intensity community health worker intervention to promote newborn and child health in Northern Nigeria. Int J Women's Health. 2013;5:717-28.

33. Findley SE, Uwemedimo OT, Doctor HV, Green C, Adamu F, Afenyadu GY. Early results of an integrated maternal, newborn, and child health program, Northern Nigeria, 2009 to 2011. BMC Public Health. 2013;13:1034.

34. Gupta M, Tripathy JP, Jamir L, Sarwa A, Sinha S, Bhag C. Improving quality of home-based postnatal care by microteaching of multipurpose workers in rural and urban slum areas of Chandigarh, India: a pilot study. Adv Med Educ Pract. 2017:8:1-8.

35. Hodgins S, MCPherson R, Suvedi BK, Shrestha RB, Silwal RC, Ban B, et al. Testing a scalable community-based approach to improve maternal and neonatal health in rural Nepal. J Perinatol: official journal of the California Perinatal Association. 2010;30(6):388-95.

36. Horwood C, Butler L, Barker P, Phakathi S, Haskins L, Grant M, et al. A continuous quality improvement intervention to improve the effectiveness of community health workers providing care to mothers and children: a cluster randomised controlled trial in South Africa. Hum Resour Health. 2017;15(1):39

37. Khanal S, Sharma J, Gc VS, Dawson P, Houston R, Khadka N, et al. Community health workers can identify and manage possible infections in neonates and young infants: MINI--a model from Nepal. J Health Popul Nutr. 2011;29(3):255-64.

38. Kumar V, Mohanty S, Kumar A, Misra RP, Santosham M, Awasthi S, et al. Effect of community-based behaviour change management on neonatal mortality in Shivgarh, Uttar Pradesh, India: a cluster-randomised controlled trial. Lancet (London, England). 2008;372(9644):1151-62.

39. Manu A, Hill Z, Ten Asbroek AH, Soremekun S, Weobong B, Gyan $T$, et al. Increasing access to care for sick newborns: evidence from the Ghana Newhints cluster-randomised controlled trial. BMJ Open. 2016;6(6):e008107.

40. Mascarenas DN, Wurzburger R, Garcia BN, Tomedi A, Mwanthi MA. The promise of home visitation by community health workers in rural Kenya: A protective effect that reduces neonatal illness. Educ Health (Abingdon, England). 2015;28(3):181-6.

41. McConnell M, Ettenger A, Rothschild CW, Muigai F, Cohen J. Can a community health worker administered postnatal checklist increase healthseeking behaviors and knowledge?: evidence from a randomized trial with a private maternity facility in Kiambu County, Kenya. BMC Pregnancy Childbirth. 2016;16(1):136.

42. Nalwadda CK, Guwatudde D, Waiswa P, Kiguli J, Namazzi G, Namutumba $\mathrm{S}$, et al. Community health workers - a resource for identification and referral of sick newborns in rural Uganda. Tropical Med Int Health. 2013;18(7):898-906.

43. Nalwadda CK, Waiswa P, Kiguli J, Namazzi G, Namutamba S, Tomson G, et al. High compliance with newborn community-to-facility referral in eastern Uganda:an opportunity to improve newborn survival. PLoS One. 2013;8(11):e81610.

44. Namazzi G, Okuga M, Tetui M, Muhumuza Kananura R, Kakaire A, Namutamba S, et al. Working with community health workers to improve maternal and newborn health outcomes: implementation and scale-up lessons from eastern Uganda. Glob Health Action. 2017;10:1345495.

45. Nsibande D, Doherty T, ljumba P, Tomlinson M, Jackson D, Sanders D, et al. Assessment of the uptake of neonatal and young infant referrals by community health workers to public health facilities in an urban informal settlement, KwaZulu-Natal, South Africa. BMC Health Serv Res. 2013;13:47. 
46. Soofi S, Cousens S, Turab A, Wasan Y, Mohammed S, Ariff S, et al. Effect of provision of home-based curative health services by public sector healthcare providers on neonatal survival: a community-based cluster-randomised trial in rural Pakistan. Lancet Glob Health. 2017;5(8):e796-806.

47. Tripathy P, Nair N, Sinha R, Rath S, Gope RK, Rath S, et al. Effect of participatory women's groups facilitated by Accredited Social Health Activists on birth outcomes in rural eastern India: a cluster-randomised controlled trial. Lancet Glob Health. 2016;4(2):e119-28.

48. Waiswa P, Pariyo G, Kallander K, Akuze J, Namazzi G, Ekirapa-Kiracho E, et al. Effect of the Uganda Newborn Study on care-seeking and care practices: a cluster-randomised controlled trial. Glob Health Action. 2015;8:24584

49. Gebremedhin T, Daka DW, Alemayehu YK, Yitbarek K, Debie A. Process evaluation of the community-based newborn care program implementation in Geze Gofa district, south Ethiopia: a case study evaluation design. BMC Pregnancy Childbirth. 2019;19(1):492.

50. Goel AD, Gosain M, Amarchand R, Sharma H, Rai S, Kapoor SK, et al. Effectiveness of a Quality Improvement Program Using Difference-in-Difference Analysis for Home Based Newborn Care - Results of a Community Intervention Trial. Indian J Pediatr. 2019:86(11):1028-35.

51. J. Limaye R, Ballard Sara A, Ahmed N, Ohkbuo S, Deka S, Mickish Gross

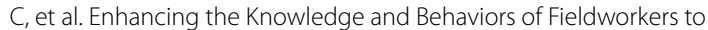
Promote Family Planning and Maternal, Newborn, and Child Health in Bangladesh Through a Digital Health Training Package: Results From a Pilot Study. Int Quart Commun Health Educ. 2020;40(2):143-9.

52. Mozumdar A, Khan ME, Mondal SK, Mohanan PS. Increasing knowledge of home based maternal and newborn care using self-help groups: Evidence from rural Uttar Pradesh, India. Sexual Reprod Healthcare. 2018;18:1-9.

53. Ndaba T, Taylor M, Mabaso M. Training and evaluation of Community Health Workers (CHWs): towards improving maternal and newborn survival in an urban setting in KwaZulu-Natal, South Africa. Open Publ Health J. 2019;12:406-13.

54. Rahman AE, Perkins J, Mazumder T, Haider MR, Siddique AB, Capello C, et al. Capacities of women and men to improve maternal and newborn health: Effect of a community-based intervention package in rural Bangladesh. J Glob Health. 2019;9(1):010413.

55. World Health Organization. Caring for the newborn at home: facilitator manual; 2015. Available from: https://apps.who.int/iris/bitstream/handle/ 10665/204273/9789241549295_FacilitatorNotes_eng.pdf?sequence $=2 \&$ isAllowed $=y$

56. Sacks E, Mehrtash H, Bohren M, Balde MD, Vogel JP, Adu-Bonsaffoh K, et al. The first $2 \mathrm{~h}$ after birth: prevalence and factors associated with neonatal care practices from a multicountry, facility-based, observational study. Lancet Glob Health. 2021;9(1):e72-e80.

57. Bucher S, Konana O, Liechty E, Garces A, Gisore P, Marete I, et al. Selfreported practices among traditional birth attendants surveyed in western Kenya: a descriptive study. BMC Pregnancy Childbirth. 2016;16(1):219.

58. Garces A, McClure EM, Espinoza L, Saleem S, Figueroa L, Bucher S, et al. Traditional birth attendants and birth outcomes in low-middle income countries: A review. Semin Perinatol. 2019;43(5):247-51.

59. National Health Mission Ministry of Health \& Family Welfare Government of India. About accredited social health activist (ASHA) 2020 [Available from: https://nhm.gov.in/index1.php?lang=1\&level=1\&sublinkid=150\& lid $=226$.

60. World Health Organization; Every Newborn: an action plan to end preventable deaths: 2014 [Available from: https://www.everynewborn.org/ Documents/Full-action-plan-EN.pdf.

61. World Health Organization. Standards for improving the quality of care for small and sick newborns in health facilities. Geneva: World Health Organization; 2020. Available from: https://www.who.int/publications/i/ item/9789240010765

62. World Health Organization. Quality of care for maternal and newborn health: a monitoring framework for network countries; 2019. Available from: https://www.who.int/docs/default-source/mca-documents/qedquality-of-care-for-maternal-and-newborn-health-a-monitoring-frame work-for-network-countries.pdf?sfvrsn=19a9f7d0_1

63. World Health Organization. Survive and thrive: transforming care for every small and sick newborn. Key findings. Geneva: World Health Organization; 2018. Available from: https://apps.who.int/iris/bitstream/ handle/10665/276655/WHO-FWC-MCA-18.11-eng.pdf?ua=1
64. World Health Organization. WHO guideline on health policy and system support to optimize community health worker programmes. Geneva: World Health Organization; 2018. Available from: https://apps.who.int/ iris/bitstream/handle/10665/275474/9789241550369-eng.pdf?ua=1\& ua $=1$

\section{Publisher's Note}

Springer Nature remains neutral with regard to jurisdictional claims in published maps and institutional affiliations.
Ready to submit your research? Choose BMC and benefit from:

- fast, convenient online submission

- thorough peer review by experienced researchers in your field

- rapid publication on acceptance

- support for research data, including large and complex data types

- gold Open Access which fosters wider collaboration and increased citations

- maximum visibility for your research: over $100 \mathrm{M}$ website views per year

At BMC, research is always in progress.

Learn more biomedcentral.com/submissions 